\title{
What Do We Really Know About VBID? Quality of the Evidence and Ethical Considerations for Health Plan Sponsors
}

\author{
Kathleen A. Fairman, MA, and Frederic R. Curtiss, PhD, RPh, CEBS
}

As health care proposals are debated and specific reforms are implemented, there will be a vital need for solid, credible, actionable information about the impact of current policies. ... To meet the needs of health care reform, research will need to be significantly more responsive to demands for findings that are timely and actionable. ${ }^{1}$

I n March 2009, the Agency for Healthcare Research and Quality (AHRQ) convened a meeting of "policymakers, researchers, and producers of health care data" to "begin developing a strategy to optimize the availability of information and data for enactment and implementation of health care reform." The needs described by participants were as expected: timely information about "the likely concrete effects of unique, specific policy proposals," provided with an eye to "the specific levers available to policymakers," developed with a "clear and transparent" methodology, and assessing "the impact on the public sector and consumer." It is telling that the need for "solid data" was emphasized by "veterans of past health care reform efforts," who also observed that current data needs "are much broader."

\section{Data Promulgated Versus Data Used: Is There a Credibility Gap?}

The AHRQ's envisioned role for accurate and transparent data in developing and monitoring a redesigned health care system represents an optimal scenario-if health care research "builds it," policymakers "will come." Yet, the ways in which health plan sponsors actually obtain and use information in making benefit design decisions may not match this expectation. A Diamond Management/Willis North America survey of large and small employers in a variety of industry sectors, conducted after passage of the Patient Protection and Affordable Care Act (PPACA) using an unreported sampling methodology, found that a slight majority (736 of 1,400,52.6\%) of respondents cited "in-house personnel" as their primary source of information about "the health care reform statute or regulations." Insurance brokers and carriers were cited as a primary information source by $25.1 \%$ and $6.6 \%$, respectively. Only $5.2 \%$ said that their primary information source was "free resources and tools as published by government agencies." Recent news reports also suggest that employers currently rely primarily on consultants to guide their planning for implementation of PPACA, including choices of cost-sharing levels and benefit designs. ${ }^{3}$ Similarly, only $6 \%$ of human resource and benefits managers responding to a 2010 Kaiser Family Foundation/ Health Research \& Educational Trust health benefits survey $(\mathrm{N}=2,046$, response rate $47 \%)$ reported that they "review performance indicators for their health plan's service or clinical quality," and of that small group, only 18\% reported using Healthcare Effectiveness Data and Information Set (HEDIS) measures promulgated by the National Committee for Quality Assurance. ${ }^{4}$

Various factors may explain employers' apparent reluctance or inability to use externally promulgated information about health care policy and quality. One is organizational size; large and small employers generally exhibit markedly different responses to external change. ${ }^{2,4}$ However, as we have observed previously, another possible reason for what appears to be inexplicable indifference to the guidance of external "experts" is appropriate wariness about recommendations that have not yet been tested in rigorous research. ${ }^{5}$ That is, the most skeptical decision makers may be the best informed about the limitations of available evidence. A growing body of work suggests that even widely used standards, such as ambulatory care metrics that are endorsed by key quality measurement organizations $^{6}$ and infectious disease treatment guidelines promulgated by the Infectious Diseases Society of America, ${ }^{7}$ are commonly supported primarily by expert opinion or a methodologically suboptimal evidence base. Moreover, guidelines supported solely by observational evidence and/or expert opinion are commonly refuted and replaced when subjected to the more rigorous test of a randomized controlled trial. ${ }^{8}$

\section{Slow Uptake of VBID: Information Gap or} Sensible Decision Making by Plan Sponsors?

The Rx Outcomes Adviser, a recently launched blog intended to provide health plan sponsors with actionable and evidencebased information about pharmacy benefits, highlighted in an early posting the costs and benefits of value-based insurance design (VBID), the lowering or waiving of copayments for "high-value" medications in an effort to increase their use. ${ }^{9}$ Because the blog's purpose is to help decision makers navigate the challenge of reviewing and applying health outcomes research to make well-informed policy decisions, ${ }^{10}$ a focus on the cost-effectiveness of VBID is particularly appropriate. 


\section{What Do We Really Know About VBID? \\ Quality of the Evidence and Ethical Considerations for Health Plan Sponsors}

Section 2713(a) of the PPACA calls for the creation of guidelines to "permit a group health plan and a health insurance issuer offering group or individual health insurance coverage to utilize [VBID],"11 suggesting that whether to adopt a VBID for the drug benefit may become an increasingly important question for payers.

Yet, despite being launched more than 9 years ago as "a concept that stands on science and equity" 12 and sustained by financial support from the pharmaceutical industry ${ }^{13,14}$ and enthusiastic popular press coverage ${ }^{15-17}$ VBID (initially termed "benefit-based copay") has not caught on among the majority of health plan sponsors. Recent VBID use rates are estimated at approximately $20 \%$, and plan deductibles over the past few years have generally trended higher, not lower. ${ }^{18-22}$ For example, when 507 employers with at least 1,000 employees were asked in the 2010 National Business Group on Health/Towers Watson (NBGH/TW) survey to indicate benefit design strategies that they had used during 2010, reductions in "pharmacy copays or coinsurance for those with chronic conditions" were cited by $19 \%$ of employers. Of 37 strategies mentioned in the 2010 survey, only 2 were used less often than copayment reductions: increasing the use of selective provider networks and providing incentives to use personal health records. In contrast, 23\% of employers reported having "significantly" increased "pharmacy copays, deductibles or coinsurance" in 2010; 54\% reported offering a consumer-directed (high-deductible) health plan (CDHP); and the percentage of CDHPs covering "preventive prescription drugs" at $100 \%$ (i.e., no patient cost-sharing) was just $20 \% .{ }^{18}$ When asked about their plans for 2011, 28\% of employers reported planning to significantly increase pharmacy cost-sharing requirements, and total estimated CDHP availability was expected to grow to $61 \% .{ }^{18}$ Although reluctance to expend funds on health care in a declining economy was no doubt partly responsible for these trends, it is notable that employers were willing to make investments in other areas. For example, the percentages offering programs for lifestyle behavioral change, health coaching, and smoking cessation were $50 \%, 56 \%$, and $76 \%$, respectively. ${ }^{18}$

Another indication of lukewarm interest in VBID is the less-than-enthusiastic treatment it receives from most large pharmacy benefits management (PBM) companies. This phenomenon is curious and worthy of attention because PBMs can be exceptionally customer-focused and would presumably embrace customer demands that are popular in the marketplace, since they typically do not bear financial risk (e.g., capitation) for the cost of pharmacy benefits. Yet, instead of pharmacy copayment reduction intended to improve medication adherence, PBMs focus more attention on alternative strategies that include dispensing medication in 90-day supplies, increasing direct contact between pharmacists and patients, providing targeted refill reminders to nonadherent patients, and implementing or enhancing clinical disease management programs (DMPs). ${ }^{23-28}$ The annual drug trend reports (DTRs) of PBMs, which reflect their marketplace strategies and benefit design recommendations, suggest a recognition that nonadherence is a multifaceted phenomenon encompassing negative perceptions about medications and side effects, patient characteristics (e.g., low literacy, forgetfulness), and therapeutic complexity requiring pharmacist intervention. ${ }^{24-28}$

However, the topic of VBID has not been avoided altogether by PBMs. A few PBMs have reported observational investigations of the association between out-of-pocket cost and medication use $e^{27,29,30}$ or between medication adherence and all-cause health care costs. ${ }^{31}$ In a balanced approach to VBID, a health plan-owned PBM advises against zero-dollar copayments because "even as little as $\$ 5$ per prescription gives the benefit more perceived value to members;" suggests that plan sponsors "carefully consider whether value-based pharmacy benefits are a good fit" for members with adherence of less than $80 \%$ for medications to treat diabetes, high blood pressure, or dyslipidemia; and recommends that to improve cost-effectiveness, sponsors consider copayment reductions for generic drugs only. ${ }^{28}$ These observations, and the advice of most PBMs to use a variety of tools and messaging strategies to improve adherence, are consistent with behavioral economics research suggesting that consumer purchasing behavior is neither entirely rational nor based solely on price. ${ }^{32}$

Peer-reviewed evidence about the reasons for payers' reluctance to adopt copayment reduction strategies is currently unavailable. However, popular press and industry reports suggest that major factors in the slow uptake for VBID include (a) the "potential for short-term increase in utilization and cost" with "uncertain" health benefits, ${ }^{21,33}$ (b) the possibility of "unintended incentives" that could reduce generic drug utilization if brand drug copayments are reduced too much, ${ }^{33}$ and (c) synergies between business interests and the use of alternative adherence promotion strategies. ${ }^{23}$

\section{Payer Perspectives on High Cost and Uncertain Evidence for VBID}

A PBM medical officer interviewed for an October 2009 report on novel business models in the PBM industry cited a focus on improving medication adherence as an important market niche. Although noting that medication nonadherence represents a "tremendous opportunity ... to lower medical costs, like [emergency room] visits for asthmatics," the PBM executive argued against using copayment waivers to promote adherence, largely because of the high cost of VBID relative to other strategies that the PBM advocates as more effective: "Benefit designs that eliminate copays increase compliance by 1 to 5 percent, but a company takes on a huge additional expense by absorbing the copay. We found that moving patients to [mail order pharmacy] is the single most important thing you can 


\section{What Do We Really Know About VBID? \\ Quality of the Evidence and Ethical Considerations for Health Plan Sponsors}

do to improve adherence." 23 The DTR of a health plan-owned PBM similarly acknowledges that "quantifying the [return-oninvestment] for [VBID] is challenging" because "medical costs avoided, improved quality of life, reduced absenteeism and other positive outcomes are often cited but can be lost when incentives are applied too broadly." 28

Popular press interviews with benefit design consultants reported in May 2009 also suggested that cost relative to uncertain benefit is an important consideration for employers in making decisions about VBID, with one consultant noting that because of the economic downturn "it's a little bit harder to get approval for reducing copays, especially when results are a little bit squishy" and another suggesting that growth in the copayment waiver trend is limited because "there's not a ton of data" about the effects of VBID on overall medical cost. ${ }^{21}$ Nonetheless, a November 2010 press report on adopters of VBID suggested that the estimated $18 \%$ of employers with a chronic medication copayment waiver or reduction in place as of 2009 "are convinced this [approach] works, despite an absence of rigorous research to back them up." ${ }^{20}$

Still, lack of reliable evidence about VBID may not be the only reason for tepid response to it by most PBMs. First, PBMs that own mail order pharmacies have an interest in using copayment incentives to encourage use of mail order by refill customers and might be expected for business reasons to recommend 90-day supplies, although some PBMs recommend 90-day dispensing for community pharmacies as well as mail order. ${ }^{28}$ Second, PBMs may be reluctant to recommend copayment reductions for brand medications for reasons that include client preference and higher profit margins on generic than brand drugs because of "spread" pricing. ${ }^{23}$

Notably, however, research evidence suggests that both of these PBM business interests are congruent with the needs of health care consumers. That is, consistent with PBM recommendations, mail order use is cost-effective for plan sponsors $^{34}$ and positively associated with adherence to chronic medication therapy, ${ }^{35,36}$ although randomized trials of the effects of mail order pharmacy use on patient outcomes are clearly needed. ${ }^{37}$ Also supporting PBM recommendations are the findings of AHRQ-funded comparative effectiveness analyses suggesting that generic medications for high-prevalence chronic conditions, such as hypertension and diabetes, ${ }^{38,39}$ on average provide equivalent therapeutic effect at equivalent or better safety - a remarkable bargain for patients considering that 90-day supplies of generic drugs to treat high-prevalence chronic conditions are commonly available for $\$ 10-\$ 12$ in large community pharmacies. ${ }^{40}$

\section{Proposal to Offset VBID Costs: Higher Cost Sharing for "Low-Value" Services}

VBID proponents rightly point out that the net total cost of a VBID program consisting only of copayment reductions "critically depends on whether the incremental spending on the targeted services, such as hypertension medication, can be offset through a decrease in adverse events, such as hospitalizations." ${ }^{41}$ In other words, does a health plan sponsor that pays for both medical and pharmacy benefits and incurs higher pharmacy benefit costs because of reducing or waiving copayments for medications to treat high-prevalence chronic conditions (e.g., diabetes, hypertension, dyslipidemia) reap the benefit of healthier enrollees who incur fewer catastrophic medical events (e.g., myocardial infarctions [MIs], strokes) as a result of increased medication use? More importantly, do health plan members-who ultimately pay a portion of the cost of health policy decisions in their share of health plan premiums-experience increased, decreased, or unchanged health benefits when the health plan sponsor implements VBID copayment reduction?

A transparent "plausibility calculator" analysis, designed and reported by Melnick and Motheral in the March 2010 issue of JMCP, suggests that "health plan sponsors are highly unlikely to experience net savings by implementing VBID programs, even under generous assumptions, for 2 reasons." ${ }^{42}$ First, price elasticity for medications is generally low in commercially insured groups, meaning that most copayment reductions go to patients who would have been equally compliant without the copayment savings. Second, in a population of commercially insured enrollees "with varying risk levels," the baseline risk of avoidable expensive medical events (e.g., emergency room [ER] visits and hospitalizations) is low, meaning that it is mathematically nearly impossible for increased medication compliance to prevent a sufficient number of expensive events to offset the costs of copayment reductions. ${ }^{42}$

Advocates of VBID have argued based on "break-even" economic modeling that VBID "can be effective" 43 but acknowledge that "direct medical savings from increased use of services with strong evidence of clinical benefit are unlikely to finance the entire [VBID] investment in the short term." ${ }^{41}$ Thus, these VBID proponents support "investments in processes to define low-value care" and a benefit design that "couples cost-sharing reductions for high-value services with cost-sharing increases for services not identified as high value." ${ }^{41}$ This suggestion has led to an important emerging issue for employers considering VBID adoption-provider and patient acceptance of higher levels of cost-sharing for services deemed "low-value." 19,41,44

\section{The Payer's Dilemma: Value to Whom?}

Methods for defining a "low-value" service are in their nascence and are far from straightforward. Fendrick et al. (2010) have suggested that services should be defined as "low-value" if they "result in harm-for example, services with D designation that are discouraged by the [U.S.] Preventive Services Task Force" (USPSTF)—or, more broadly, if their cost is "deemed too expensive for the health benefits produced." ${ }^{41}$ 


\section{What Do We Really Know About VBID? \\ Quality of the Evidence and Ethical Considerations for Health Plan Sponsors}

Health economist James Robinson has argued that "low-value" services should be subsets of "high-cost health services," such as "biopharmaceuticals, implantable medical devices, advanced imaging modalities, and specialized surgical procedures." ${ }^{44}$ Various methods would be used to determine which highcost services would fall into the "low-value" subset, depending on the clinical circumstances. For biopharmaceuticals, for example, Robinson proposes that value might be defined based on the patient's "clinical indication, disease severity, and comorbidities," perhaps in conjunction with practice setting characteristics including "physician specialty, the presence of care coordination, and patient education services." He suggests that U.S. Food and Drug Administration (FDA) approval might also be used as an indication of value (i.e., drugs used off-label would be subject to higher patient cost sharing), perhaps in conjunction with a drug compendium or "an authoritative, evidence-based care pathway." ${ }^{4}$ For implantable devices (e.g., stents, pacemakers), he proposes that payers "cover the basicfunction device, leaving the patient to buy up to a higherfunction alternative-unless the higher-function device were known to offer a clinically better outcome to this particular type of patient" as determined by "the health plan's medical management professionals in consultation with the patient's physician." ${ }^{44}$ And, for common surgeries, such as knee replacements, "the insurer could specify a contribution that it would make, with the contribution based on the payment rate for the most efficient provider team in the local market. The patient would be assigned responsibility for paying the extra costs incurred if a higher-price provider team is chosen." ${ }^{44}$ Putting aside the complexity of designing, maintaining, and administering a system like that envisioned by Robinson, 2 important and potentially controversial issues are apparent.

Whose "Evidence-Based Conclusion" Prevails in Determining "Value?" First, key organizations, viewing the same evidence, often reach different conclusions about the value of medical services. For example, the suggestion by Fendrick et al. ${ }^{41}$ to assign a "low-value" designation to USPSTF "D" services is reasonable, but the USPSTF currently has a D designation for teaching women to perform monthly breast self-examinations $(B S E)^{45}$ and, at this writing, appears poised to give prostate cancer screenings for men in all age groups a D designation in an upcoming meeting. ${ }^{46}$ In contrast, screening guidelines promulgated by the American Cancer Society (ACS) describe BSE training and prostate cancer screening as options that should be made available to patients and providers, depending on the patient's level of risk and personal preferences. ${ }^{47-49}$

Similarly, the USPSTF currently has a C designation for mammography before the age of 50 years, meaning that the USPSTF "recommends against routinely providing the service" because "there is at least moderate certainty that the net benefit [of the service] is small" after accounting for both benefits and harms associated with the screening process; these harms include primarily "psychological harms, unnecessary imaging tests and biopsies in women without cancer, and inconvenience due to false-positive screening results" and "overdiagnosis," defined as the detection and treatment "of cancer that would never have become clinically apparent." Nonetheless, the USPSTF recognizes the possibility of "considerations that support providing the service in an individual patient," including "the patient's values regarding specific benefits and harms." ${ }^{50}$ In contrast, the ACS recommends annual mammograms beginning at 40 years of age "and continuing for as long as a woman is in good health." ${ }^{1}$ The American College of Radiology (ACR) goes a step further in describing the value of screening mammography for women aged 40 to 49 years, calling the USPSTF recommendations "ill advised and dangerous" and "unconscionable," describing annual mammography screening for women aged 40 years or older as "one of the major health care advances of the past 40 years," and arguing that the USPSTF "selectively reviewed the literature, ignoring hundreds of well-regarded studies on the subject." ${ }^{2}$ This controversy leaves a payer that is trying to define cost-sharing levels based on "value" with an obvious and seemingly irreconcilable conundrum: which evidence-based conclusion should the payer adopt in determining the value of mammography for women aged 40 to 49 years - that of the USPSTF, the ACS, or the ACR?

Ethical Considerations in Deeming Services "Low-Value" When Evidence is Uncertain. Second and more important, a policy of redirecting scarce resources from one patient group (users of high-cost medical services, often for catastrophic illness) to another patient group (users of chronic medication therapy for high-prevalence conditions, often for primary prevention) has profound ethical implications that require thoughtful consideration of the evidence about the proposed policy change. In other words, consistent with the principles of comparative effectiveness research, appropriate and ethical resource allocation requires reliable and valid evidence about the costs and benefits of available alternatives. Yet, as Choudhry et al. (2010) observed in a recent review, "there is a paucity of data to indicate for which services cost sharing should be increased," as well as a "lack of evidence" about whether drug copayment reductions "will yield better health outcomes and lead to reductions in other health care costs." dence makes the resource allocation shifts suggested by VBID proponents ethically questionable at the present time.

These ethical implications become even more cogent when one considers the possibility that reduced brand drug copayments could potentially incentivize patients to use brand medications for therapeutic purposes that could be served with generics, a phenomenon of "unintended incentives." 33 Such incentives reduce the affordability of the benefit, both overall 


\section{What Do We Really Know About VBID? \\ Quality of the Evidence and Ethical Considerations for Health Plan Sponsors}

and - a point that often goes unnoticed-for the individual patient who pays an unnecessarily high, albeit reduced, copayment for the brand drug.

The clinical implications of potentially encouraging greater first-line brand drug use should also be thoughtfully considered because the risks and benefits of newer medications are sometimes not as fully understood prior to FDA approval as they are in the postmarketing phase. The history of rosiglitazone-a top-selling diabetes drug that was initially approved in 1999 but "significantly" restricted by the FDA in September 2010 because new studies suggested that it elevated cardiovascular event risk-provides a case in point. ${ }^{53,54}$

Early Responses to Defining "Low-Value" Services. Given these uncertainties, it is perhaps not surprising that early efforts to implement VBID programs encompassing both copayment reductions for "high-value" services and copayment increases for "low-value" services have been met with skepticism and controversy. In March 2010, Kaiser Health News reported that 5 insurers in Oregon had begun offering a benefit design that provided free or low-cost physician visits and prescription drugs for certain chronic conditions (asthma, congestive heart failure, diabetes, depression, heart disease, chronic bronchitis, and emphysema) but required much higher patient cost sharing for "treatments deemed overused." ${ }^{5}$ Patients using targeted "overused" treatments—such as knee or hip replacement, coronary artery bypass surgery, stent placement, hysterectomy, certain imaging examinations, and ER visits-would pay double the usual plan deductible, double the office visit copayment, and up to one-half of hospitalization and ER cost, up to an annual out-of-pocket maximum of $\$ 1,500$ for individuals and $\$ 3,000$ for families. Only 1 employer, a steel manufacturer, adopted the plan offering, and its head of benefits estimated that only $7 \%$ of workers would select it. ${ }^{55}$

Detractors of this and similar VBIDs argue that the designs fall into a "danger zone of limiting access to medical care" and that they represent "too much of a blunt instrument." 55 For example, not every patient with heart disease can be treated medically instead of surgically, and "while researchers say that, overall, too many hysterectomies are performed, women with uterine cancer have little choice." ${ }^{55}$ When the state of Oregon implemented a similar VBID for its public employees in 2010, its planning group "ruled out including cardiac treatments and hysterectomy in the higher-cost [category of] coverage because doing so was considered too contentious." ${ }^{56}$

\section{Inaccurate Descriptions Hamper Efforts to Evaluate VBID}

The important task of finding answers to the question of VBID's effectiveness in improving patient health has been complicated by deficiencies in the base of evidence about pharmacy benefit copayment change. We noted in a 2008 editorial that evidence suggesting an effect of VBID on medication adherence was scant and methodologically nontransparent. ${ }^{57}$ We have also noted that the "case" for the negative effect of typical copayment increases on adherence has been made primarily with research employing observational designs in which association was sometimes erroneously equated with causation; quasiexperimental (pre vs. post with comparison group) studies of typical copayment increases in commercially insured groups have generally found positive outcomes for patients and plan sponsors. ${ }^{8,58-61}$

Unfortunately, much of the literature on cost sharing has tended to overstate or misstate previous research findings, suggesting that cost sharing had a greater influence on medication adherence than was actually documented in the original work. For example, in discussions of cross-sectional analyses comparing higher versus lower cost sharing levels, one sometimes sees references to "price responsiveness" to "[copayment] changes" when no copayment change was measured ${ }^{58}$ or to "adherence" outcomes from studies that included no measures of adherence; ${ }^{57}$ and seemingly small but often substantively important discrepancies are common. In a recent example, a 2008 study by Sedjo and $\operatorname{Cox}^{62}$ of changes in statin utilization following simvastatin (Zocor) patent expiration was among the studies cited in the introduction to a research article to support a statement that medication adherence increases by $2 \%-5 \%$ in the first year after VBID implementation. ${ }^{63}$ Sedjo and Cox did find that following simvastatin patent expiration and the resulting change from a brand to generic copayment (not a VBID program implementation), the medication possession ratio (MPR) for simvastatin users increased by a mean adjusted $0.52 \%$, compared with an MPR decline of $2.02 \%$ for users of brand statins other than simvastatin, who experienced no copayment decrease. However, they also found that among patients who experienced the greatest copayment decreases measured in the study, more than $\$ 15$, price elasticity was - 0.02 - that is, no meaningful price responsiveness; and, they found that the percentages of patients whose MPR increased from less than $80 \%$ before patent expiration to at least $80 \%$ after patent expiration were $10.5 \%$ in the simvastatin group and $10.0 \%$ in the group using other brand statins - that is, no meaningful difference. ${ }^{62}$

A more serious discrepancy appeared in the introduction to a recently published research article, in which a study by Huskamp et al. (2003) was cited to support the statement that "prescription drug benefits that shift greater costs to consumers or increase barriers to access can result in lower rates of drug treatment, poorer adherence, and increased rates of treatment discontinuation." ${ }^{29}$ This description is inconsistent with the actual finding of Huskamp et al. that a change from a single-tier $\$ 7$ copayment to a 3 -tier $\$ 8 / \$ 15 / \$ 30$ benefit, but not a change from a 2 -tier $\$ 6 / \$ 12$ to a 3 -tier $\$ 6 / \$ 12 / \$ 24$ benefit, was associated with a reduced probability of using medication in 3 therapy classes (proton pump inhibitors, 


\section{What Do We Really Know About VBID? \\ Quality of the Evidence and Ethical Considerations for Health Plan Sponsors}

angiotensin-converting enzyme [ACE] inhibitors, and statins). ${ }^{61}$ More importantly, Huskamp et al. found that treatment discontinuation rates were significantly higher for patients who experienced a $\$ 23$ copayment increase (from $\$ 7$ to $\$ 30$ ) but not for patients who experienced a $\$ 12$ copayment increase (from $\$ 12$ to $\$ 24$ ). And, perhaps because of type 1 error or an unmeasured confounder, among patients taking ACE inhibitors, treatment discontinuation rates were lower (not higher) for the patients who experienced a copayment increase from $\$ 12$ to $\$ 24$ than for patients whose copayments remained unchanged at \$12-that is, persistence with ACE inhibitor therapy was better for patients with a higher copayment. ${ }^{61}$

The Huskamp et al. study has been inaccurately described elsewhere including a 2008 commentary, which indicated that "when an employer increased cost-sharing requirements by about $\$ 10$ to $\$ 20$ per prescription ...21\% of patients stopped taking their medication for high cholesterol (compared with $11 \%$ in a control group);" ${ }^{64}$ the actual research finding by Huskamp et al. for a group experiencing a copayment increase of approximately $\$ 10$ was that 3 of 33 (9.1\%) statin users whose copayment increased by $\$ 12$ versus 1 of 25 (4.0\%) statin users without a copayment increase discontinued statin use, a nonsignificant difference $(P=0.45) .{ }^{61}$

The same commentary, an assessment of policy implications from the Rand Health Insurance Experiment (RHIE) and selected observational studies, indicated that by discouraging use of appropriate health care services, cost sharing "could lead to additional hospitalization, emergency department visits, and even death." ${ }^{44}$ The RHIE did find that higher levels of cost sharing led to reduction in use of health care services, including both those deemed essential and nonessential by RHIE investigators; yet, the RHIE found that these service use reductions had no effects on health except for a few minor outcomes (e.g., vision, dental, and increase of an average 3 millimeters mercury $[\mathrm{mm} \mathrm{Hg}]$ in diastolic blood pressure) that were limited to low-income RHIE enrollees only. ${ }^{65,66}$ In contrast to the commentary's portrayal, RHIE authors even argued in 1987 and 1992 that their finding of "enormous potential savings" from cost sharing, with "little apparent health impact on the kind of people who typically are covered under employer health insurance," may have prompted plan sponsors to increase coinsurance and deductibles in the years immediately following the RHIE's publication, resulting in large health care cost savings nationwide. ${ }^{65,67}$

\section{New Observational Evidence About VBID Copayment Reduction}

Since publication of our earlier observations about deficiencies in research on VBID, ${ }^{8,57}$ new copayment reduction studies using nonrandomized comparison groups have been published, ${ }^{29,62,63,68-71}$ and an additional study ${ }^{31}$ measured the association between medication adherence and all-cause health care costs (Appendix). Although all the VBID studies provided evidence that implementation of VBID might have a small favorable effect on medication adherence, none provided the information that payers need to make an informed decision about VBID because of serious problems in reporting, program design, and effect calculation.

No Information About Generic Utilization. None of the new studies of VBID reported its effect on generic utilization, ${ }^{29,63,68-71}$ an especially important omission for programs in which copayment reductions either included brand drugs ${ }^{29,68,70}$ or were limited to brand drugs. ${ }^{69,71}$ Failure to report the effects of brand drug copayment decreases on generic drug utilization is especially problematic because previous observational investigations have found an association between prescription drug cost-sharing increases and increased use of lower-cost medications (i.e., generic and preferred brand drugs) in the same therapeutic class. ${ }^{58,61}$

No Information About Payer Cost. None of the new VBID studies reported the cost of the intervention to the payer. ${ }^{29,63,68-71}$ A report by Gibson et al. (2011a) of a program in which coinsurance rates for brand antidiabetic drugs were reduced-from $20 \%$ for tier 2 and 35\% for tier 3 to the 10\% level previously in place only for generic medications-is especially notable because it purported to show a favorable return-on-investment (ROI) attributable to medical cost offsets but actually measured total costs, not payer costs. ${ }^{71}$ In other words, the calculation ignored the cost to the employer for the copayment waivers (i.e., the cost shift from patient to payer); thus, its results do not represent ROI from the payer perspective. The report also indicated significant effects for VBID only for a subgroup of patients enrolled in a DMP but did not report the cost of the DMP. This omission of DMP costs is especially important because the program was intensive, including nurse telephone outreach, coaching, and monitoring, in addition to numerous written educational components. ${ }^{71}$ Thus, despite the indication in the article's title that VBID coupled with a DMP "produced savings," the study did not address that research question.

In another report by Gibson et al. (2011b) of a copayment reduction intervention for medications to treat diabetes, asthma, and hypertension, the authors "raise the prospect that this program may have saved the company money by reducing other medical costs" because "clinical effects such as changes in glucose levels, blood pressure, and lung functioning might have occurred," but no assessment of these measures was made, and the report's quantitative analysis indicated no significant association between VBID and any of 3 measures of spending (pharmaceutical, medical, or total) during the 3-year post-implementation period. ${ }^{70}$ The study report also transparently disclosed 2 important confounding factors-a DMP was phased in for the VBID employer during the postimplementation period, and the VBID employer was a pharmaceutical manufacturer that provided its brand drugs free of 
TABLE 1 Illustration of the Mathematical Effect of Removing Patients Making Medication Switches Before Calculating Discontinuation Rates

\begin{tabular}{|c|c|c|c|c|c|}
\hline Hypothetical Plan & Number of Users & $\begin{array}{l}\text { Number Switching to } \\
\text { Generic Medication }\end{array}$ & $\begin{array}{c}\text { Number Discontinuing } \\
\text { Therapy }\end{array}$ & $\begin{array}{c}\text { Actual } \\
\text { Discontinuation Rate }\end{array}$ & $\begin{array}{l}\text { Discontinuation } \\
\text { Rate After Removing } \\
\text { Switching Patients } \\
\text { from Denominator }\end{array}$ \\
\hline Plan A-VBIDa & 100 & 0 & 10 & $10.0 \%$ & $10.0 \%$ \\
\hline Plan B-tiered benefit ${ }^{a}$ & 100 & 20 & 10 & $10.0 \%$ & $12.5 \%$ \\
\hline
\end{tabular}

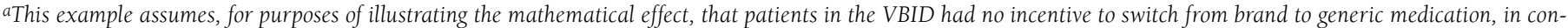
trast to patients in the traditional tiered benefit plan.

VBID = value-based insurance design.

charge to employees. Unfortunately, the brand drugs were not named and the DMP was not described, making it difficult for decision makers to interpret or use the study results in estimating the costs and benefits of VBID. Finally, as in the other recent report by Gibson et al., the authors indicated that "the program was mostly cost-neutral to the company;" however, the measure of expenditures was "eligible charges," which was not defined specifically but appears to be a total (rather than a net after copayment) that does not represent the health plan sponsor's costs. ${ }^{70}$

Unfortunately, in addition to failing to report the cost of the intervention to the health plan sponsor, none of the new VBID study reports contained even enough quantitative information for readers to calculate the intervention cost. Although most provided some information about mean copayment amounts paid per claim by the intervention and/or comparison groups before and/or after the intervention, only a few provided quantitative information for both time periods and groups, and none provided information about utilization (number of claims), which is essential to translating cost per claim into total cost. Additionally, tier-specific utilization data were not included in any of the new VBID study reports but are necessary to determine whether utilization shifts to drugs in higher or lower tiers affected payers' ingredient cost expenditures.

Problems in Study Design and/or Reporting. Several problems in recent VBID research reports, including discrepancies between study methods and either methodological or clinical guidelines, are apparent (Appendix). For example, in an analysis of therapy discontinuation rates for a VBID program for antidiabetic medications, Chang et al. (2010) removed from the denominator patients who made a medication switch from one antidiabetic subclass to another (e.g., from a thiazolidinedione [TZD] to metformin or to a sulfonylurea). ${ }^{29}$ This decision had the mathematical effect of inflating the discontinuation rate overall, and especially in the presence of even appropriate and desired switches from brand to therapeutically equivalent generic drugs, thereby systematically biasing the analysis to find higher "discontinuation" rates for the comparison group than the VBID group (Table 1). Unfortunately, the report does not contain the patient subgroup counts necessary to calculate unbiased discontinuation rates for the study groups.

Less serious but still important is a problem with attributed causal linkage that appears in a transparent and clearly reported analysis by Roebuck et al. (2011) of the association between medication adherence and all-cause health care costs. ${ }^{31}$ In that analysis, the authors made no assessment of whether the observed all-cause utilization could reasonably be clinically attributed to medication nonadherence (e.g., cardiovascular events vs. automobile accidents); the authors chose instead to rely solely on fixed-effects statistical modeling techniques to establish causal linkage, a suboptimal method for observational analysis. ${ }^{72}$ Additionally, the authors assumed that a patient with a chronic disease diagnosis (heart failure, diabetes, hypertension, or dyslipidemia) but without pharmacy claims had medication adherence of zero, regardless of whether any medication was prescribed. This decision excludes the possibility of nonpharmacologic interventions based on lifestyle modification and is, although appropriate for heart failure, inconsistent or only partly consistent with treatment guidelines for the other 3 disease states. ${ }^{73-75}$

Another problem common to varying degrees in the new VBID studies is lack of specificity in the descriptions of sample construction. For example, only 1 included a sample selection flowchart to enable the reader to determine the effect of each sample inclusion and exclusion criterion, ${ }^{69}$ although this information is considered a standard for research reporting. ${ }^{72}$ Moreover, it was difficult to determine key details, such as the specific criteria used to define a "user" of a particular drug class or to qualify for DMP entry, in many reports. Similarly, in many VBID reports it was difficult or impossible to identify the preintervention values and/or the absolute change amounts for the outcome measures.

Still No Randomized Trials. As Roebuck et al. candidly acknowledge, even a well-done multivariate statistical analysis controlling for fixed effects (e.g., as a proxy for "healthy adherer" effects) is "not as good as a randomized controlled trial in establishing causality." ${ }^{11}$ The report by Gibson et al. of the brand antidiabetic drug copayment reduction program is 


\section{What Do We Really Know About VBID? \\ Quality of the Evidence and Ethical Considerations for Health Plan Sponsors}

especially notable in this regard because its findings strongly suggest that the "effects" of the program were actually due to confounding. Specifically, the study found that among DMP participants, compliance with recommended screening and monitoring (i.e., primary care provider visits, hemoglobin Alc tests, lipid tests, and urinalysis) was higher for VBID enrollees than for comparison group patients. ${ }^{71}$ However, the study report indicated that the VBID program changed pharmacy copayments only. There is no logically apparent causal linkage between pharmacy copayments and receipt of guideline-based medical care, and the study authors offered none in the report. Like the finding of Dormuth et al. (2009) that patients compliant with statin therapy were less likely than noncompliant patients to have automobile and workplace accidents, ${ }^{76}$ the findings of Gibson et al. sound a cautionary note for those who attempt to equate association with causation; the resulting conclusions may be biologically or logically implausible.

In contrast, an observational analysis by Maciejewski et al. (2010) is commendable for its inclusion of a comparison group of patients treated with therapy classes in which copayments were reduced in both the VBID intervention and comparison groups. The authors made the reasonable case that the lack of VBID "effect" in these classes, coupled with the positive association of VBID with adherence in the other study drug classes, strengthened the internal validity of their findings. ${ }^{63} \mathrm{~A}$ study by Choudhry et al. of copayment elimination for statins and copayment reduction for clopidogrel, effective January 1, 2007, appears to have good internal validity ${ }^{68}$ however, the intervention was conducted among enrollees whose employer coupled widely publicized copayment reductions with intensive educational interventions in 2002, ${ }^{77}$ making the context and external validity of the 2007 intervention unclear.

\section{Costs and Benefits of VBID Interventions}

The 2 new VBID studies with the strongest internal validity, one by Choudhry et al. and the other by Maciejewski et al., suggest a VBID effect size of approximately 1.5 to 4 percentage points in adherence measured by MPR or proportion of days covered (PDC). ${ }^{63,68}$ Effect sizes of about 2.6 to 4.0 percentage points annually were reported previously by Chernew et al. (2008) for copayment reductions (for tier 1/tier 2/tier 3) from $\$ 5 / \$ 25 / \$ 45$ to $\$ 0 / \$ 12.50 / \$ 22.50$ for diabetes drugs, statins, and antihypertensive drugs (ACE inhibitors and angiotensin II receptor blockers $[\mathrm{ARBs}]){ }^{78}$ Despite the statistical significance of MPR or PDC changes of 2 to 4 percentage points measured using large samples, these changes represent only 7 to 15 added days of therapy per year on average (e.g., $0.02 \times 365=7.3$ days).

The costs and benefits of these small adherence improvements have not yet been reported. In a previous editorial on the study by Chernew et al., we used national data to compensate for missing information in the study report and estimated that the approximate payer cost per member per year (PMPY) for that VBID program after full phase-in was $\$ 18.60$ ( $\$ 1.86$ million per year in a drug plan with 100,000 members) for statins to achieve a 3.4 percentage point increase in MPR, or about 12 added days of therapy each year on average. ${ }^{57}$ Although the VBID for statin drugs reported recently by Choudhry et al. ${ }^{68}$ was limited to patients using prescription medications for diabetes or cardiovascular disease, one could reasonably assess the cost of providing free statins to all statin users in a health plan by using the mean pre-intervention statin copayment of $\$ 24$ per claim reported by Choudhry et al., coupled with the use prevalence rate of $12.1 \%$ and 10.0 claims per user per year reported by a PBM for $2009^{26}$ to calculate an estimated VBID cost of approximately \$29 PMPY $(12.1 \% \times 10.0 \times \$ 24)$. For the VBID group in the study by Maciejewski et al., the cost would be lower because the intervention consisted of a generic copayment waiver; however, the estimate of VBID cost would be somewhat misleading because in both the VBID and comparison groups, all tier 3 brand drugs in the study drug classes were set to a tier 2 copayment. Putting aside that limitation, and assuming that the pre-intervention generic dispensing ratio for statins (38\%) was unchanged in the post-intervention period, the cost of waiving the approximately $\$ 11$ generic copayment in the study by Maciejewski et al. would be $\$ 5.06$ PMPY $(38 \% \times 12.1 \% \times 10.0 \times \$ 11)$.

Three key points about these calculations are noteworthy for payers. First, these figures illustrate the conclusion reached by Melnick and Motheral based on their VBID plausibility calculator that mathematically, it is nearly impossible for a health plan sponsor to achieve cost neutrality in VBID programs using medical cost offsets, with the possible exception of programs applied only to generic medications. ${ }^{42}$ Assuming that a private payer incurs a cost of approximately $\$ 60,000$ per patient for a major cardiovascular event (in 2006, costs per hospital stay billed to private insurance were $\$ 44,733$ for coronary artery disease, $\$ 54,697$ for MI, and $\$ 44,239$ for stroke), ${ }^{79}$ achieving cost neutrality for a VBID program that costs $\$ 29$ PMPY in a plan with 100,000 members would require prevention of an additional 48 cardiovascular events per year $(\$ 2.9$ million divided by $\$ 60,000$ ). Thus, using clinical trial data as indicators of the baseline effectiveness of statins in preventing major cardiovas-

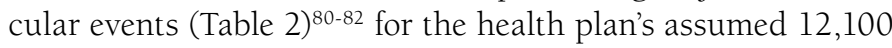
statin users (use prevalence of $12.1 \% \times 100,000$ ) and assuming a baseline MPR of 50\%-80\%, a VBID copayment reduction program that costs $\$ 29$ PMPY would have to increase the effectiveness of statin treatment by approximately $41 \%-49 \%$ in secondary prevention (e.g., an increase of 48 over a baseline of 97 to 118 patients in whom events are prevented annually) and $68 \%-79 \%$ in primary prevention-despite increasing medication adherence by only about 4\%-6\% (3 percentage points improvement over a baseline MPR of 50\%-80\%) to break even. As VBID proponents have observed, additional cost offsets 


\section{What Do We Really Know About VBID? \\ Quality of the Evidence and Ethical Considerations for Health Plan Sponsors}

\section{TABLE 2 Effectiveness of Statin Treatment in Preventing Major Cardiovascular}

Events in a Hypothetical 100,000-Member Health Plan

\begin{tabular}{|c|c|c|c|c|c|c|}
\hline Study & $\begin{array}{c}\text { Description of } \\
\text { Events Avoided } \\
\text { by Statin Treatment }\end{array}$ & $\begin{array}{c}\text { Per-Patient } \\
\text { Probability of } \\
\text { Having at Least } \\
1 \text { Avoided Event } \\
\text { During Follow- } \\
\text { Up Period }\end{array}$ & $\begin{array}{l}\text { Length of } \\
\text { Follow-Up } \\
\text { Period } \\
\text { (Years) }\end{array}$ & $\begin{array}{l}\text { Annual } \\
\text { Probability } \\
\text { of Event } \\
\text { Avoidance }^{\mathrm{a}}\end{array}$ & $\begin{array}{l}\text { Number } \\
\text { of Treated } \\
\text { Patients }\end{array}$ & $\begin{array}{c}\text { Annual } \\
\text { Number of } \\
\text { Patients with } \\
\text { at Least } 1 \\
\text { Avoided Event }\end{array}$ \\
\hline $\begin{array}{l}\text { LIPID Secondary } \\
\text { Prevention Trial } 81\end{array}$ & $\begin{array}{l}\text { Events ( } 30 \text { deaths, } \\
28 \text { nonfatal MIs, and } \\
9 \text { nonfatal strokes) } \\
\text { were avoided in an } \\
\text { unduplicated } 48 \text { patients } \\
\text { for every } 1,000 \text { treated. }\end{array}$ & 0.048 & 6.1 & 0.0080 & 12,100 & 97 \\
\hline $\begin{array}{l}\text { Meta-analysis of all statin } \\
\text { users, secondary prevention } 82\end{array}$ & $\begin{array}{l}\text { Events were avoided in } 48 \\
\text { patients per } 1,000 \text { treated. }\end{array}$ & 0.048 & 5 & 0.0098 & 12,100 & 118 \\
\hline $\begin{array}{l}\text { Meta-analysis of all statin } \\
\text { users, primary prevention } 82\end{array}$ & $\begin{array}{l}\text { Events were avoided in } 25 \\
\text { patients per } 1,000 \text { treated. }\end{array}$ & 0.025 & 5 & 0.0051 & 12,100 & 61 \\
\hline $\begin{array}{l}\text { JUPITER, primary } \\
\text { prevention }^{80}\end{array}$ & $\begin{array}{l}0.59 \text { composite endpoint } \\
\text { events per } 100 \text { person- } \\
\text { years of follow-up. }{ }^{d}\end{array}$ & NA & NA & 0.0059 & 12,100 & $71^{d}$ \\
\hline
\end{tabular}

a Annual rate is derived algebraically from the cumulative probability formula: $C=1-(1-a)^{n}$, where $C=$ cumulative probability, a= annual probability, and $n=$ number of years ${ }^{84}$ - that is, $a=1-(1-C)^{1 / n}$.

${ }^{b}$ Number of treated patients is derived from $12.1 \%$ annual statin use prevalence ${ }^{26}$ times assumed health plan population of 100,000 enrollees

${ }^{c}$ Number of treated patients $\times$ annual avoided event rate. Annual probabilities shown in table are rounded to the fourth decimal.

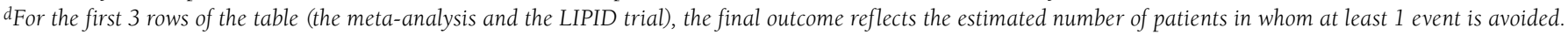
For the last row of the table (JUPITER), the final outcome reflects the estimated number of avoided events.

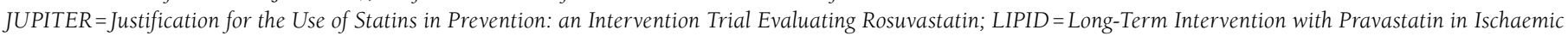
Disease; $M I=$ myocardial infarction; NA=not applicable.

from improved worker productivity (e.g., reduced absenteeism and disability days), although not easily measured, are possible for active employee groups, ${ }^{43}$ however, it is difficult to imagine that these effects would be substantial given the small size of the medication adherence effects.

Second, the results of the Maciejewski et al. analysis suggest, consistent with PBM observations, that the adherence effects of dispensing medication in 90-day supplies may overwhelm those of VBID. In the Maciejewski et al. analysis, enrollees with at least 1 pharmacy claim for a 90-day supply had adherence rates 17 to 22 percentage points higher than those of patients without any 90-day supplies. ${ }^{63}$ Notably and unfortunately, none of the other new VBID studies reported utilization rates of 90-day supplies or mail order pharmacy or analyzed the effect of 90-day supplies on medication adherence.

Third, the need to calculate these "back-of-the-envelope" estimates from published research articles highlights deficiencies in the base of evidence about copayment reduction programs, especially for payers that need actionable, quantitative estimates of the impact of adherence promotion strategies on economic and clinical outcomes.

\section{What to Expect When You're Expecting Information About VBID}

In their 2008 report of the association of VBID with MPR changes of 2.6 to 4.0 percentage points, Chernew et al. predicted that "because clinical evidence supports adherence to these medications, we expect health improvements, although we do not quantify them in this study." 78 In an accompanying press release from the sponsoring institution, the study's lead author speculated that "while future studies need to be done to actually quantify this specifically, there is considerable evidence that use of the classes of medication in this study will reduce the frequency of adverse clinical events and associated hospitalizations and ER visits." ${ }^{15}$ However, about 2 years later, the research team reported that "preliminary statistical analysis of the spending data" for the VBID had "indicated considerable uncertainty surrounding estimates of the impact of the [VBID] intervention on aggregate spending," preventing econometric analyses of the data and prompting the investigators to develop a pharmacoeconomic model instead of analyzing the actual observed outcomes for the sample. ${ }^{43}$ Unfortunately, no data on hospitalizations or ER visits-consequences of the "adverse clinical events" that the investigators had suggested would be prevented by the VBID—were reported.

Similarly, an analysis plan for a study of the MHealthy initiative, a VBID program that was implemented for University of Michigan employees and their dependents with diabetes on July 1, 2006, was published in April 2009. ${ }^{83}$ The analysis plan indicated that study follow-up would end 30 months 


\section{What Do We Really Know About VBID? \\ Quality of the Evidence and Ethical Considerations for Health Plan Sponsors}

after implementation, or approximately January 2009, and that the analysis would assess the primary outcomes of medication utilization and adherence, as well as secondary outcomes including health care costs and utilization rates for outpatient visits, ER visits, and hospitalizations. ${ }^{83}$ Although the MHealthy study follow-up was scheduled to end more than 2 years ago at this writing, to date the only reported findings of which we are aware include a brief mention, reported in a 2010 review article, of "preliminary results" indicating that the MHealthy intervention was associated with "a 7 percent increase in adherence to blood pressurelowering medication and a nonsignificant 4 percent increase in adherence to statins." ${ }^{11}$

Against this shortfall of evidence promised but not yet reported, several reasons for a "caveat emptor" approach to VBID research are apparent, including the following key points.

Isolated Significant Findings. Because of cumulative type 1 (false positive) error, it is mathematically expected that at least 1 finding in a series of numerous statistical tests will be statistically significant solely because of chance. For example, in 20 statistical tests at an alpha of 0.05 , the probability of at least 1 false positive finding is $64 \% .{ }^{84}$ In the presence of publication bias, these multiple tests are not necessarily apparent to readers of a single research article. We encourage health plan sponsors to be mindful of the history of VBID research reporting (or nonreporting) in considering the results reported in any single publication, especially for hospitalizations and ER visits.

Causal Linkages. In viewing published results of observational studies of VBID programs, payers should consider whether the findings are plausible. For example, one would not expect large medical cost offsets from tiny medication adherence gains, large adherence gains from small cost-sharing changes, or changes in a measure of quality of care that is not affected by pharmacy copayments (e.g., receipt of guideline-based medical care, such as examinations and laboratory tests). Although understanding complex nuances of methodological and statistical techniques may be difficult for managed care decision makers who lack research training, consideration of basic clinical and practical causal logic is not difficult and will go a long way toward assessing the validity of VBID studies.

Total Cost Versus Health Plan Sponsor Cost: A Major Difference for Payers. To date, 3 assessments of costs associated with VBID have either measured ${ }^{70,71}$ or estimated ${ }^{43}$ change in total cost, including both the payer cost and the patient cost share. Although this method is not inherently erroneous because it is common for health policy research to examine cost outcomes from a societal perspective, it produces a result that is uninformative for health plan sponsors making a decision about VBID. The financial effects of VBID on plan sponsors are the sum of (a) increased medication adherence (an effect that is captured in the total cost measure), and (b) the reduction in copayment (an effect that is not captured in the total cost measure). Because of the inelasticity (lack of price responsiveness) in drug purchasing behavior in commercially insured groups, a calculation of total cost change in a VBID program will produce a small estimated effect that understates the actual cost of VBID to the payer. Yet, only 1 of the 3 reports, the economic "break-even" analysis by Chernew et al., ${ }^{43}$ transparently disclosed in the study report the implications of the analytic perspective for plan sponsors. Thus, when provided with information about VBID costs and benefits, health plan sponsors should check carefully to determine if payer costs were measured.

Overextension. Completion of the first randomized trial of a copayment reduction intervention is expected in early 2011. ${ }^{11}$ That study, the Post-MI FREEE (Free Rx and Economic Evaluation), is a test of eliminating copayments for secondary prevention medications (statins, beta-blockers, ACE inhibitors, and ARBs) for patients aged 64 years or younger following hospitalization for MI. ${ }^{85}$ Because the baseline probability of adverse cardiovascular events is higher in a patient population with a previous MI than in the population of cardiovascular medication users as a whole, the likelihood of finding clinical benefits is higher in this patient sample than in a typical patient population in which medications are used both for primary and secondary prevention. Yet, an unfortunately common occurrence in health policy research is the overextension of findings from a study sample manifesting one set of characteristics to a larger population with completely different clinical or demographic characteristics. We have previously pointed out the frequent inappropriate extensions of a study conducted in a small group of low-income elderly with numerous chronic illnesses to healthier patient populations and to different outcomes-even to outcomes that were not studied in the original research ${ }^{86}$ In assessing the information presented in popular press accounts and literature reviews, payers should compare the assertions made about the Post-MI FREEE findings with the study report-or the study abstract for decision makers who lack the time to read the entire report-to determine if findings are represented accurately or misstated.

\section{VBID: What Should Health Plan Sponsors Do Now?}

We predicted in 2008 that managed care was approaching a crossroads at which policymakers would have to decide whether to reject cost-sharing policies based on high-quality evidence in favor of weaker, but more vigorously promoted, evidence $^{58}$ That issue has become more acute and ethically important with the recent suggestions that the costs of drug copayment reductions-often for primary prevention using brand medications in therapeutic classes with generic alternatives-should be offset by increasing cost-sharing 


\section{What Do We Really Know About VBID? \\ Quality of the Evidence and Ethical Considerations for Health Plan Sponsors}

requirements for patients using expensive treatments for serious or catastrophic illness. Assessment both of the evidence and, more importantly, the limitations of the evidence regarding VBID suggests 4 important steps going forward.

First, as Choudhry et al. observed in their recent review, important questions about the effects of drug copayment reductions on clinical and economic outcomes "should be answered before [VBID] is used more widely."11 Because VBID has been associated with only minimal medication adherence increases documented only in observational research, and because no health or medical utilization outcomes (e.g., ER or hospital use) have yet been reported for VBID programs, the evidence is insufficient to support expanding its use at the present time.

Second, managed care decision makers should refuse to accept studies that lack transparent reporting necessary to make even basic estimates of the costs and benefits of VBID. Nontransparent study reports do not provide useful information and should not be used for policymaking. For promulgators of research information, the logical corollary is that continuing to publish suboptimal work will eventually cause decision makers to be indifferent to study findings-exactly the opposite of the goal that the AHRQ has set for evidencebased decision making in health care policy.

Third and related, although it would seem that health care decision makers should not have to be responsible for critical appraisal of the information provided in peer-reviewed articles, it appears that such critique is unfortunately necessary in costsharing research because of a pattern of inaccurate statements about research findings. In reading literature reports about VBID, health care decision makers will find it helpful to read the source materials - at least the study abstract and the results tables if time is short-instead of relying solely on secondary descriptions of what previous research has shown. Summary study tables including critical appraisal of the evidence, such as those that we have reported here and in previous JMCP issues, ${ }^{58}$ as well as that reported by Motheral in the current issue $^{87}$ are also helpful, and we encourage other health policy researchers to provide summaries of this type for health care decision makers.

Fourth, and most important from a policy perspective, deliberations about whether to fund drug copayment reductions, especially for primary prevention, by directing scarce resources away from a subset of prescribed medical and pharmaceutical treatments should demand high-quality evidence. Yet at this writing, nearly a decade after pharmacy benefit copayment reduction was initially proposed as a means to improve the outcomes of patients with chronic health conditions, health plan sponsors have little of the information that they need to assess the costs and benefits of VBID. Available evidence is of suboptimal quality, much of it so opaque that it is uninterpretable; outcomes critically important to enrollees and health plan sponsors, such as cost to the payer and effects on generic drug utilization and patient health, remain either unexamined or unreported; and the only randomized trial of VBID of which we are aware, the Post-MI FREEE, is laudable for its design and transparency but limited to secondary prevention. An evidence base that falls so far short of the AHRQ's ideal for health care policy research-timely, clear, transparent, solid, and actionable - should be viewed as an example of how not to inform health care system change.

\section{Authors}

KATHLEEN A. FAIRMAN, MA, is Associate Editor and Senior Methodology Reviewer, and FREDERIC R. CURTISS, PhD, RPh, CEBS, is Editor-in-Chief of the Journal of Managed Care Pharmacy.

AUTHOR CORRESPONDENCE: Kathleen A. Fairman, MA, Academy of Managed Care Pharmacy, 100 North Pitt St., Suite 400, Alexandria, VA 22314. Tel.: 602.867.1343;

E-mail: kfairman@amcp.org.

\section{DISCLOSURES}

The authors report no financial conflicts of interest related to the subjects or products discussed in this article. Fairman reports that she works and volunteers a few hours each month in nursing homes, primarily with bedbound patients who have catastrophic illnesses.

\section{REFERENCES}

1. Agency for Healthcare Research and Quality. Filling the information needs for healthcare reform: expert meeting summary and identification of next steps. Available at: http://www.ahrq.gov/data/hinfosum.htm. Accessed January 24, 2011

2. Diamond Management $\&$ Technology Consultants. The Health Care Reform Survey 2010. Willis. November 10, 2010. Available at: http://www. willis.com/documents/publications/Services/Employee_Benefits/Health_ Care_Reform_Survey_2010_V9.pdf. Accessed January 24, 2011.

3. Mattioli D. Firms feel pain from health law. WSJ. December 13, 2010 Available at: http://online.wsj.com/article/SB10001424052748703727804576 $011791786531256 . h t m l$. Accessed December 13, 2010.

4. The Kaiser Family Foundation and Health Research \& Educational Trust. Employer Health Benefits 2010 Annual Survey. Available at: http://ehbs.kff. org/pdf/2010/8085.pdf. Accessed November 23, 2010.

5. Fairman KA, Curtiss FR. Selling real-world health care research to reluctant buyers: evidence-based education or marketing a defective product? J Manag Care Pharm. 2009;15(3):294-96. Available at: http://www.amcp.org/ data/jmcp/294-296.pdf. Accessed November 23, 2010.

6. De Brantes F, Wickland PS, Williams JP. The value of ambulatory care measures: a review of clinical and financial impact from an employer/ payer perspective. Am J Manag Care. 2008;14(6):360-68. Available at: http:// www.ajmc.com/media/pdf/AJMC_08jun_Brantes360to68.pdf. Accessed November 23, 2010

7. Lee DH, Vielemeyer O. Analysis of overall level of evidence behind Infectious Diseases Society of America practice guidelines. Arch Intern Med. 2011;171(1):18-22. 


\section{What Do We Really Know About VBID? \\ Quality of the Evidence and Ethical Considerations for Health Plan Sponsors}

8. Fairman KA, Curtiss FR. Still looking for health outcomes in all the wrong places? Misinterpreted observational evidence, medication adherence promotion, and value-based insurance design. J Manag Care Pharm. 2009;15(6):501-07. Available at: http://www.amcp.org/data/jmcp/501-507. pdf.

9. Motheral B. Value-based insurance design: a bargain at $\$ 10$ per day? Rx Outcomes Adviser. December 15, 2010. Available at: http://rxoutcomesadviser.wordpress.com/2010/12/15/value-based-insurance-design-a-bargain-at10-per-day/. Accessed January 24, 2011

10. Motheral B. About Rx Outcomes Adviser. Available at: http://rxoutcomesadviser.wordpress.com/about/. Accessed January 24, 2011.

11. Choudhry NK, Rosenthal MB, Milstein A. Assessing the evidence for value-based insurance design. Health Aff (Millwood). 2010;29(11):1988-94.

12. Fendrick AM, Smith DG, Chernew ME, Shah SN. A benefit-based copay for prescription drugs: patient contribution based on total benefits, not drug acquisition cost. Am J Manag Care. 2001;7(9):861-67. Available at: http:// www.ajmc.com/media/pdf/AJMC2001sepFendrick861_867.pdf. Accessed January 24, 2011

13. University of Michigan, Center for Value-Based Insurance Design. Funding. Available at: http://www.sph.umich.edu/vbidcenter/about/funding. html. Accessed January 24, 2011.

14. Fendrick AM, Edlin ML. Value-based insurance design landscape digest. National Pharmaceutical Council. July 2009. Available at: http://www. vbhealth.org/wp-content/uploads/2009/08/NPC_VBIDreport_7-22-09.pdf. Accessed December 10, 2010.

15. University of Michigan Department of Public Relations and Marketing Communications. The co-pay connection: lowering drug co-pays for chronic disease patients increases use of important preventive medicines, rigorous study shows. January 8, 2008. Available at: http://www.med.umich.edu/ opm/newspage/2008/drugcopay.htm. Accessed January 23, 2011

16. Fuhrmans V. New tack on copays: cutting them. WSJ. May 8, 2007:D1. Available at: http://www.sph.umich.edu/vbidcenter/news/pdfs/WSJ\%20 Copays\%20May\%208\%20(2).pdf. Accessed January 25, 2011.

17. Hensley S. Chopping copays makes medicines more attractive. NPR. November 2, 2010. Available at: http://www.npr.org/blogs/ health/2010/11/02/130998493/chopping-copays-makes-statins-plavix-moreattractive. Accessed January 24, 2011

18. National Business Group on Health/Towers Watson. Raising the bar on health care: moving beyond incremental change. 2010. Available at: http:// www.towerswatson.com/assets/pdf/1345/TW_15565_NBGH.pdf. Accessed January 24, 2011.

19. Andrews M. doctors play crucial role in tying health care choices to value. Shots-NPR's Health Blog. November 30, 2010. Available at: http:// www.npr.org/blogs/health/2010/11/30/131690967/doctors-play-crucial-rolein-tying-health-care-choices-to-value. Accessed January 24, 2011.

20. Blanton K. Health care: spend more, save more. CFO.com. November 18 , 2010. Available at: http://www.cfo.com/article.cfm/14540665/c_14540734. Accessed December 10, 2010.

21. Kertesz L. Economic problems put brakes on Rx copay waiver trend: senior management wait for more evidence of health care savings. Business Insurance. May 11, 2009. Available at: http://www.businessinsurance.com/ apps/pbcs.dll/article?AID=9999100027607\&template=printart. Accessed February 12, 2011

22. Anonymous. Health benefit cost growth accelerates to $6.9 \%$ in 2010 Mercer. November 17, 2010. Available at: http://www.mercer.com/pressreleases/1400235. Accessed December 10, 2010.

23. Reinke T. Large PBMs transform old business models. Manag Care 2009;18(10):20-21, 25-28. Available at: http://www.managedcaremag.com/ archives/0910/0910.pbms.html. Accessed December 14, 2010.

24. Medco. 2010 drug trend report: Solving the healthcare cost/quality equation. Available at: http://www.drugtrend.com/art/drug_trend/pdf/ DT_Report_2010.pdf. Accessed December 14, 2010.
25. Walgreens Health Initiatives. Pharmacy benefit solutions: 2010 trend report. Available at: http://www.walgreenshealth.com/pdf/newsletterreport/ PBS12843_TrendReport_web2.pdf. Accessed December 14, 2010.

26. Miller S, Cox E, Nease B, et al. 2009 Drug trend report: solving for America's $\$ 163$ billion in pharmacy-related waste. April 2010. Available at: http://www.express-scripts.com/research/studies/drugtrendreport/2009/ dtrFinal.pdf. Accessed January 24, 2011.

27. Lofberg P, Brennan T, Greer L, et al. Insights 2010: evolving pharmacy care. Available at: https://www.caremark.com/portal/asset/CVSCaremark_ Insights_2010.pdf. Accessed January 24, 2011.

28. Prime Therapeutics. 2010 drug trend insights: where smart pharmacy benefit management meets results. Available at: http://www.primetherapeutics.com/pdf/2010primedrugtrends.pdf. Accessed January 24, 2011.

29. Chang A, Liberman JN, Coulen C, Berger JE, Brennan TA. Value-based insurance design and antidiabetic medication adherence. The American Journal of Pharmacy Benefits. 2010;2(1):39-45.

30. Gleason PP, Starner CI, Gunderson BW, Schafer JA, Sarran HS. Association of prescription abandonment with cost share for high-cost specialty pharmacy medications. J Manag Care Pharm. 2009;15(8). Available at: http://www.amcp.org/data/jmcp/648-658.pdf.

31. Roebuck MC, Liberman JN, Gemmill-Toyama M, Brennan TA. Medication adherence leads to lower health care use and costs despite increased drug spending. Health Aff (Millwood). 2011;30(1):91-98.

32. Fairman KA. What pharmacy benefit designers need to know about perception and reality: never forget the elephant in the pharmacy. J Manag Care Pharm. 2008;14(4):387-94. Available at: http://www.amcp.org/data/jmcp/ JMCPMaga_387-394.pdf.

33. Fitch K, Iwasaki K, Pyenson B. Value-based insurance designs for diabetes drug therapy: actuarial and implementation considerations. Prepared for Takeda Pharmaceuticals, North America, Inc., by Milliman. December 1, 2008. Available at: http://publications.milliman.com/research/health-rr/ pdfs/vbid-diabetes-drug-therapy-RR12-01-08.pdf. Accessed January 24, 2011

34. Federal Trade Commission. FTC issues report on PBM ownership of mail-order pharmacies. September 6, 2005. Available at: http://www.ftc.gov/ opa/2005/09/pharmbenefit.shtm. Accessed February 7, 2011.

35. Doru OK, Schmittdiel JA, Dyer WT, et al. Mail-order pharmacy use and adherence to diabetes-related medications. Am J Manag Care. 2010;16(1):3340. Available at: http://www.ajmc.com/media/pdf/AJMC_2010Jan_ Duru_33to40.pdf. Accessed December 16, 2010.

36. Devine S, Vlahiotis A, Sundar H. A comparison of diabetes medication adherence and healthcare costs in patients using mail order pharmacy and retail pharmacy. J Med Econ. 2010;13(2):203-11.

37. Brown TA, Rickles NM. Mail-order versus local pharmacies on adherence: study methods make for unfair comparison [letter and author reply]. Am J Manag Care. 2010;16(3):226-28. Available at: http://www.ajmc.com/ media/pdf/AJMC_2010marLtrToEd_226to228.pdf. Accessed December 16, 2010

38. Matchar DB, McCrory DC, Orlando LA, et al. Comparative effectiveness of angiotensin-converting enzyme inhibitors (ACEIs) and angiotensin II receptor antagonists (ARBs) for treating essential hypertension. November 2007. Available at: http://www.effectivehealthcare.ahrq.gov/ehc/products/12/45/ACEI_ARBFullReport.pdf. Accessed January 13, 2011.

39. Bolen S, Wilson L, Vassy J, et al. Comparative effectiveness and safety of oral diabetes medications for adults with type 2 diabetes. Agency for Healthcare Research and Quality. July 2007. Available at: http://www.effectivehealthcare.ahrq.gov/repFiles/OralFullReport.pdf. Accessed January 13, 2011

40. Choudhry NK, Shrank WH. Four dollar generics-increased accessibility, impaired quality assurance. N Engl J Med. 2010;363(20):188587. Available at: http://www.nejm.org/doi/full/10.1056/NEJMp1011625. Accessed January 25, 2011. 


\section{What Do We Really Know About VBID? \\ Quality of the Evidence and Ethical Considerations for Health Plan Sponsors}

41. Fendrick AM, Smith DG, Chernew ME. Applying value-based insurance design to low-value health services. Health Aff (Millwood). 2010;29(11):201721

42. Melnick SJ, Motheral BR. Is "value-based" value wasted? Examining value-based insurance designs through the lens of cost-effectiveness. J Manag Care Pharm. 2010;16(2):130-33. Available at: http://www.amcp.org/data/ jmcp/130-133.pdf.

43. Chernew ME, Juster IA, Shah M, et al. Evidence that value-based insurance can be effective. Health Aff (Millwood). 2010;29(3):530-36.

44. Robinson JC. Applying value-based insurance design to high-cost health services. Health Aff (Millwood). 2010;29(11):2009-16.

45. U.S. Preventive Services Task Force. Screening for breast cancer. November 2009, updated July 2010. Available at: http://www.uspreventiveservicestaskforce.org/uspstf/uspsbrca.htm. Accessed January 25, 2011.

46. Hobson K. Prevention task force cancels Nov. meeting; would have included prostate screening vote. WSJ Health Blog. October 26, 2010. Available at: http://blogs.wsj.com/health/2010/10/26/prevention-taskforce-cancels-nov-meeting-would-have-included-prostate-screening-vote/. Accessed January 25, 2011.

47. American Cancer Society. Breast awareness and self-exam. September 15, 2010, revised January 4, 2011. Available at: http://www.cancer.org/ Cancer/BreastCancer/MoreInformation/BreastCancerEarlyDetection/breastcancer-early-detection-acs-recs-bse. Accessed January 25, 2011.

48. American Cancer Society. American Cancer Society recommendations for prostate cancer early detection. December 1, 2010. Available at: http://www.cancer.org/Cancer/ProstateCancer/MoreInformation/ ProstateCancerEarlyDetection/prostate-cancer-early-detection-acs-recommendations. Accessed January 25, 2011.

49. Brawley OW, Gansler T. Introducing the 2010 American Cancer Society prostate cancer screening guideline. CA Cancer J Clin. 2010;60(2):68-69. Available at: http://caonline.amcancersoc.org/cgi/reprint/60/2/68. Accessed January 25,2011

50. U.S. Preventive Services Task Force. Screening for breast cancer: U.S. Preventive Services Task Force recommendation statement. Ann Intern Med. 2009;151(10):716-26. Available at: http://www.uspreventiveservicestaskforce. org/uspstf09/breastcancer/brcanrs.pdf. Accessed January 25, 2011

51. American Cancer Society. American Cancer Society guidelines for the early detection of cancer. Available at: http://www.cancer.org/Healthy/ FindCancerEarly/CancerScreeningGuidelines/american-cancer-societyguidelines-for-the-early-detection-of-cancer. Accessed January 25, 2011.

52. American College of Radiology. Detailed ACR statement on ill advised and dangerous USPSTF mammography recommendations. Undated document. Available at: http://www.acr.org/MainMenuCategories/media_room/ FeaturedCategories/PressReleases/UPSTFDetails.aspx. Accessed January 6, 2011.

53. Harris G. F.D.A to restrict Avandia, citing heart risk. NY Times. September 23, 2010. Available at: http://www.nytimes.com/2010/09/24/ health/policy/24avandia.html?_r=2. Accessed January 25, 2011.

54. U.S. Food and Drug Administration. FDA significantly restricts access to the diabetes drug Avandia. September 23, 2010. Available at: http://www. fda.gov/NewsEvents/Newsroom/PressAnnouncements/ucm226975.htm. Accessed January 25, 2011.

55. Appleby J. Carrot-and-stick health plans aim to cut costs: potentially controversial policies are part of trend toward 'value-based design.' Kaiser Health News. March 11, 2010. Available at: http://www.kaiserhealthnews. org/Stories/2010/March/11/value-based-health-insurance.aspx. Accessed January 25, 2011

56. Kapowich JM. Oregon's test of value-based insurance design in coverage for state workers. Health Aff (Millwood). 2010;29(11):2028-32.
57. Fairman KA, Curtiss FR. Making the world safe for evidence-based policy: let's slay the biases in research on value-based insurance design. $J$ Manag Care Pharm. 2008;14(2):198-204. Available at: http://www.amcp.org/ data/jmcp/JMCPMaga_March\%2008_198-204.pdf.

58. Fairman KA. The future of prescription drug cost-sharing: real progress or dropped opportunity? J Manag Care Pharm. 2008;14(1):70-82. Available at: http://www.amcp.org/data/jmcp/JMCPMaga_JanFeb\%2008_070-082.pdf

59. Fairman KA, Motheral BR, Henderson RR. Retrospective, long-term follow-up study of the effect of a three-tier prescription drug copayment system on pharmaceutical and other medical utilization and costs. Clin Ther. 2003;25(12):3147-66

60. Motheral B, Fairman KA. Effect of a three-tier prescription copay on pharmaceutical and other medical utilization. Med Care. 2001;39(12):1293304.

61. Huskamp HA, Deverka PA, Epstein AM, Epstein RS, McGuigan KA, Frank RG. The effect of incentive based formularies on prescription-drug utilization and spending. N Engl J Med. 2003;349(23):2224-32. Available at: http://www.nejm.org/doi/full/10.1056/NEJMsa030954.

62. Sedjo RL, Cox ER. Lowering copayments: impact of simvastatin patent expiration on patient adherence. Am J Manag Care. 2008;14(12):81318. Available at: http://www.ajmc.com/media/pdf/AJMC_08dec_ Sedjo_813to818.pdf. Accessed December 28, 2010.

63. Maciejewski ML, Farley JF, Parker J, Wansink D. Copayment reductions generate greater medication adherence in targeted patients. Health Aff (Millwood). 2010;29(11):2002-08

64. Chernew ME, Newhouse JP. What does the RAND Health Insurance Experiment tell us about the impact of patient cost sharing on health outcomes? Am J Manag Care. 2008;14(7):412-14. Available at: http://www.ajmc com/media/pdf/AJMC_08jul_Chernew_412to414_.pdf. Accessed January 23, 2011

65. Manning WG, Newhouse JP, Duan N, Keeler EB, Liebowitz A, Marquis MS. Health insurance and the demand for medical care: evidence from a randomized experiment. Am Econ Rev. 1987;77(3):251-77.

66. Brook RH, Ware JE, Rogers WH, et al. The effect of coinsurance on the health of adults: results from the RAND Health Insurance Experiment. The RAND Corporation. R-3055-HHS. 1984. Available at: http://www.rand.org/ pubs/reports/R3055.html. Accessed February 9, 2011.

67. Keeler EB. Effects on cost sharing on use of medical services and health. J Med Pract Manage. 1992;8:317-21. Available at: http://www.rand.org/content/dam/rand/pubs/reprints/2005/RP1114.pdf. Accessed February 7, 2011.

68. Choudhry NK, Fischer MA, Avorn J, et al. At Pitney Bowes, value-based insurance design cut copayments and increased drug adherence. Health Aff (Millwood). 2010;29(11):1995-2001.

69. Zeng F, An JJ, Scully R, Barrington C, Patel BV, Nichol MB. The impact of value-based benefit design on adherence to diabetes medications: a propensity score-weighted difference in difference evaluation. Value Health. 2010;13(6):846-52.

70. Gibson TB, Wang S, Kelly E, et al. A value-based insurance design program at a large company boosted medication adherence for employees with chronic illnesses. Health Aff (Millwood). 2011;30(1):109-17.

71. Gibson TB, Mahoney J, Ranghell K, Cherney BJ, McElwee N. Valuebased insurance plus disease management increased medication use and produced savings. Health Aff (Millwood). 2011;30(1):100-08.

72. Vandenbroucke JP, von Elm E, Altman DG, et al. Strengthening the reporting of observational studies in epidemiology (STROBE): explanation and elaboration. Ann Intern Med. 2007;147:W-163-W-194. Available at: http:// www.annals.org/cgi/reprint/147/8/W-163.pdf. Accessed January 15, 2011.

73. National Cholesterol Education Program. ATP III guidelines at-a-glance quick desk reference. Available at: http://www.nhlbi.nih.gov/guidelines/cholesterol/atglance.pdf. Accessed January 15, 2011. 


\section{What Do We Really Know About VBID? \\ Quality of the Evidence and Ethical Considerations for Health Plan Sponsors}

74. U.S. Department of Health and Human Services, National High Blood Pressure Education Program. JNC 7 express: the seventh report of the Joint National Committee on Prevention, Detection, Evaluation, and Treatment of High Blood Pressure. December 2003. Available at: http://www.nhlbi.nih. gov/guidelines/hypertension/express.pdf. Accessed January 15, 2011.

75. Nathan DM, Buse JB, Davidson MB, et al. Medical management of hyperglycemia in type 2 diabetes: a consensus algorithm for the initiation and adjustment of therapy. Diabetes Care. 2009;32(1):193-203. Available at: http://www.ncbi.nlm.nih.gov/pmc/articles/PMC2606813/pdf/193.pdf. Accessed January 15, 2011.

76. Dormuth CR, Patrick AR, Shrank WH, et al. Statin adherence and risk of accidents: a cautionary tale. Circulation. 2009;119(15):2051-57. Available at: http://circ.ahajournals.org/cgi/reprint/119/15/2051. Accessed January 18, 2011.

77. Mahoney JJ. Reducing patient drug acquisition costs can lower diabetes health claims. Am J Manag Care. 2005;11(5 Suppl):S170-S176. Available at: http://www.ajmc.com/media/pdf/A128_05augMahoneyS170tol76.pdf. Accessed December 10, 2010.

78. Chernew ME, Shah MR, Wegh A, et al. Impact of decreasing copayments on medication adherence within a disease management environment. Health Aff (Millwood). 2008;27(1):103-12.

79. Andrews RM. The national hospital bill: the most expensive conditions by payer, 2006. HCUP statistical brief \#59. September 2008. Available at: http://www.hcup-us.ahrq.gov/reports/statbriefs/sb59.pdf. Accessed January 17, 2011.

80. Ridker PM, Danielson E, Fonseca FA, et al.; JUPITER Study Group. Rosuvastatin to prevent vascular events in men and women with elevated c-reactive protein. N Engl J Med. 2008;359(21):2195-207. Published online ahead of print on Nov 9, 2008. Available at: http://www.nejm.org/doi/ full/10.1056/NEJMoa0807646. Accessed January 23, 2011.
81. Anonymous. Prevention of cardiovascular events and death with pravastatin in patients with coronary heart disease and a broad range of initial cholesterol levels. The Long-Term Intervention with Pravastatin in Ischaemic Disease (LIPID) Study Group. N Engl J Med. 1998;339(19):1349-57. Available at: http://www.nejm.org/doi/full/10.1056/NEJM199811053391902. Accessed January 24, 2011

82. Baigent C, Keech A, Kearney PM, et al. Efficacy and safety of cholesterollowering treatment: prospective meta-analysis of data from 90,056 participants in 14 randomised trials of statins. Lancet. 2005;366(9493):1267-78.

83. Spaulding A, Fendrick AM, Herman WH, et al. A controlled trial of value-based insurance design - the MHealthy: Focus on Diabetes (FOD) trial. Implement Sci. 2009;4:19. Available at: http://www.ncbi.nlm.nih.gov/pmc/ articles/PMC2673203/pdf/1748-5908-4-19.pdf. Accessed January 18, 2011.

84. The formula for calculating the cumulative probability of type 1 error is: $C=1-(1-a)^{n}$, where $C=$ cumulative probability, $a=$ single-test alpha, and $\mathrm{n}=$ number of tests. Kaul S, Diamond GA. Trial and error. How to avoid commonly encountered limitations of published clinical trials. J Am Coll Cardiol. 2010;55(5):415-27.

85. Choudhry NK, Brennan T, Toscano M, et al. Rationale and design of the Post-MI FREEE trial: a randomized evaluation of first-dollar drug coverage for post-myocardial infarction secondary preventive therapies. Am Heart J. 2008;156(1):31-36. Available at: http://www.ncbi.nlm.nih.gov/pmc/articles/ PMC2697130/pdf/nihms78751.pdf. Accessed January 18, 2011.

86. Fairman KA. Accuracy in pharmacoeconomic literature review: lessons learned from the Navajo Code Talkers. J Manag Care Pharm. 2008;14(9):88691. Available at: http://www.amcp.org/data/jmcp/886-891.pdf.

87. Motheral BR. Pharmaceutical step-therapy interventions: a critical review of the literature. J Manag Care Pharm. 2011;17(2):143-55. Available at: http:// www.amcp.org/data/jmcp/143-155.pdf.

Editors' note to online readers: All JMCP articles contain hyperlinks to the source documents for free-access references. These hyperlinks are embedded in the reference numbers cited in the text as well as in the list of references at the end of each article. 


\section{What Do We Really Know About VBID? \\ Quality of the Evidence and Ethical Considerations for Health Plan Sponsors}

\section{APPENDIX Summary of Recent Observational Studies of Copayment Reductions and Medication Adherence}

\begin{tabular}{l|l}
\hline Chang (2010)29 & $\begin{array}{l}\text { Overview: Study of copayment reductions for antidiabetic medications-free generics and insulin, reductions in copayments for tier } \\
\text { 2 brand drugs, no change for tier 3, effective January 1, 2007; study period was January 1, 2006, through December 31, 2007. }\end{array}$ \\
\hline Sample & $\begin{array}{l}\text { Enrollees with at least l claim for an antidiabetic medication during the study period, classified as initiators (no claims in 2006) } \\
\text { and continuers/discontinuers (use in } 2006 \text { including final } 45 \text { days of the year); all were continuously enrolled throughout the study } \\
\text { period. }\end{array}$
\end{tabular}

Groups $\quad$ Intervention: 3 PBM clients without concurrent educational or DSM programs; $\mathrm{n}=20,173$ (however, outcomes were reported for only 2,538 patients). Copayments changed from $\$ 15$ to $\$ 0$ for generic; $\$ 30$ to a range of $\$ 10$ - $\$ 15$ for tier 2 ; a range of $\$ 30-\$ 35$ for tier 3 in both periods; mean copayments changed from $\$ 28$ to $\$ 0$ for insulin and from $\$ 21$ to $\$ 10$ for OADs.

Comparison: PBM clients without VBID; $n=190,889$ (however, outcomes were reported for only 8,912 patients), matched on "adjudication platform," client type, benefit characteristics including "mail or retail coverage," and "mean out-of-pocket costs at the group level;" and by demographic characteristics and geographic region at the individual level. Copayments were $\$ 10$ for tiers 1 and 2 in both periods, ${ }^{b}$ and ranged from $\$ 30-\$ 35$ for tier 3 in both periods; insulin mean changed from $\$ 23$ to $\$ 28$ and OAD mean was $\$ 18$ in both periods.

\begin{tabular}{|c|c|}
\hline Analysis & $\begin{array}{l}\text { Comparisons of MPR, treatment initiation and DC rates pre-intervention vs. post-intervention for intervention and compar } \\
\text { groups; DC rate calculations excluded patients switching to a different therapeutic antidiabetic subclass. Logistic regressior } \\
\text { of discontinuation and linear regression models of MPR adjusted for age, sex, and mail order use. }\end{array}$ \\
\hline
\end{tabular}

Results $\quad$ - Treatment initiation rates were $2.3 \%$ intervention vs. $1.6 \%$ comparison group.

- Among initiators, DC rates were $16.0 \%$ intervention vs. $24.3 \%$ comparison; MPR was 0.857 intervention vs. 0.858 comparison.

- Among continuers, DC rates were $26.0 \%$ intervention vs. $29.8 \%$ comparison; MPR change was +0.049 intervention vs. -0.023 comparison.

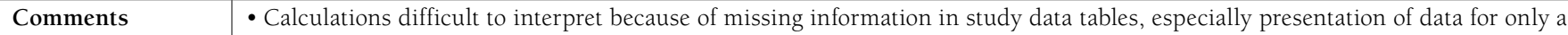
small fraction of study cases.

- Pre-intervention values of most outcome variables not reported, making it difficult to interpret the practical/clinical significance of study results.

- Prior to the intervention, use prevalence rates were about 1-2 percentage points higher, and the percentage with MPR more than $80 \%$ was much lower, in the VBID group than the comparison group; MPR change results could represent RTM, but pre-intervention MPRs were not documented, making RTM effects difficult to ascertain.

- The effect of $\$ 4$ generic programs among large community pharmacies is unknown; it is possible that higher treatment "initiation" rates reflect switch from $\$ 4$ generics (not in database and paid by patient) to $\$ 0$ generics (in database and paid by health plan sponsor).

- The decision to exclude from the DC calculation patients who made a subclass switch (a) masked the potentially positive result of switching to lower cost medication and (b) artificially inflated DC rates in presence of elevated switch rates (Table 1 ), thereby biasing the analysis to find higher DC rates in the comparison group.

- Insulin copayments increased by $22 \%$ in the comparison group from pre- to post-intervention.

\begin{tabular}{|c|c|}
\hline Choudhry (2010)68 & $\begin{array}{l}\text { Overview: Study of elimination of all statin copayments for patients with vascular disease or diabetes and reduction of copayments } \\
\text { for clopidogrel, effective January } 1,2007 \text {. }\end{array}$ \\
\hline Sample & $\begin{array}{l}\text { Patients who from January } 2006 \text { through December } 2007 \text { either (a) had at least } 1 \text { statin claim and proxy measure for diabetes and } \\
\text { vascular disease (at least } 1 \text { claim for diabetes medication or supply, beta blocker, or platelet inhibitor) or (b) had at least } 1 \text { claim for } \\
\text { clopidogrel; there was no continuous enrollment requirement for sample inclusion. }\end{array}$ \\
\hline Groups & $\begin{array}{l}\text { Intervention: Employees and dependents of Pitney Bowes; } n=2,051 \text { statins and } 779 \text { clopidogrel; mean copayments changed from } \\
\$ 24.18 \text { to } \$ 0.60 \text { for statins and from } \$ 17.22 \text { to } \$ 8.86 \text { for clopidogrel. }\end{array}$ \\
\hline & $\begin{array}{l}\text { Comparison: Commercially insured enrollees of BCBS-NJ who used the same PBM; } \mathrm{n}=38,174 \text { statins and } 11,627 \text { clopidogrel; mean } \\
\text { copayments changed from } \$ 11.80 \text { to } \$ 11.95 \text { for statins and from } \$ 10.65 \text { to } \$ 14.43 \text { for clopidogrel. }\end{array}$ \\
\hline Analysis & $\begin{array}{l}\text { Interrupted time series of monthly PDC from January } 2006 \text { through December 2007; GEE models controlled for demographics, ZIP } \\
\text { level data, and comorbidities. }\end{array}$ \\
\hline Results & $\begin{array}{l}\text { - Unadjusted: Statin PDC } 2.8 \text { percentage points higher for VBID than comparison "immediately after" implementation; clopidogrel } \\
\text { PDC } 4.0 \text { percentage points higher for VBID than comparison } 12 \text { months post-implementation. } \\
\text { - Adjusted: } 3.1 \text { percentage point "immediate" increase in PDC level for statins; } 4.2 \text { percentage point "immediate" increase in PDC } \\
\text { level for clopidogrel; no significant changes in slope in either group. }\end{array}$ \\
\hline Comments & $\begin{array}{l}\text { - Pitney Bowes implemented widely publicized copayment reductions and education beginning in } 2002,5 \text { years prior to this copay- } \\
\text { ment reduction; c context of present study not clear. Analysis "unable to account" for the extent of participation in DMPs that were } \\
\text { available to both study groups. } \\
\text { - Mean copayment in comparison group was essentially unchanged for statins in pre- and post-intervention periods but increased by } \\
\text { 35\% (from } \$ 10.65 \text { to } \$ 14.43 \text { ) for clopidogrel. } \\
\text { - Generic simvastatin became available in June 2006, midway through the pre-intervention period; it is not clear whether plans } \\
\text { encouraged switches to generic simvastatin during post-implementation period. } \\
\text { - Positive methodological decisions included the following: (a) days spent in a hospital or nursing home were subtracted from the } \\
\text { denominator; (b) statin PDC accounted for all drugs (i.e., switching did not count against PDC); and (c) numerous sensitivity anal- } \\
\text { yses were performed (producing similar findings). }\end{array}$ \\
\hline
\end{tabular}




\section{What Do We Really Know About VBID? \\ Quality of the Evidence and Ethical Considerations for Health Plan Sponsors}

\section{APPENDIX Summary of Recent Observational Studies of Copayment Reductions and Medication Adherence ${ }^{a}$ (continued)}

\begin{tabular}{l|l}
\hline Gibson (2011a) & $\begin{array}{l}\text { Overview: Study of reduction in copayment to 10\% for all diabetes medications, including both generic and brand, effective January } \\
1,2006 ; \text {; DMP also became available to both intervention and comparison group employees on January } 1,2006 .\end{array}$ \\
\hline Sample & $\begin{array}{l}\text { Enrollees aged } 64 \text { years or younger who either participated in DMP or opted out of DMP and were continuously enrolled in at least } 4 \\
\text { consecutive quarters from } 2005 \text { through 2008; use of antidiabetic medication was not required for sample inclusion, and the authors } \\
\text { note that "our enrollee pool may have included patients who were using diet and exercise to manage their condition." }\end{array}$ \\
\hline
\end{tabular}

Groups $\quad$ Intervention: Employees and dependents of 2 units "of a large multi-industry firm" $(\mathrm{n}=33,160) ; \mathrm{n}=1,876$ in DMP and $\mathrm{n}=328$ who opted out of DMP. Copayments for diabetes medications changed from 10\% generic, 20\% tier 2, and 35\% for tier 3 to $10 \%$ for all diabetes medications (generic and brand).

Comparison: Employees and dependents in the rest of the firm's units ( $\mathrm{n}=59,038)$; enrollees were propensity matched for probability of being in the intervention group based on demographic characteristics, health status (CCI and psychiatric diagnosis groups), employment characteristics (e.g., salary vs. hourly, active vs. retiree), relationship to employee, and ZIP-level income and education; $\mathrm{n}=1,876$ in DMP and $\mathrm{n}=328$ who opted out of DMP. Copayments remained constant at $10 \%$ generic, $20 \%$ tier 2 , and $35 \%$ tier 3 .

\begin{tabular}{l|l}
\hline Analysis & $\begin{array}{l}\text { Time-series panel data analysis of } 1 \text { baseline year (2005) and } 3 \text { post-implementation years (2006 through 2008), with calendar quar- } \\
\text { ter as unit of time; analyses were stratified by participation in DMP. Costs and utilization were analyzed using GEE, and costs were } \\
\text { measured as total payments (not payer costs). }\end{array}$ \\
\hline Results & $\begin{array}{l}\text { Among DMP participants, MPR for VBID (copayment reduction) group compared with non-VBID group was } 3.7 \text { percentage points } \\
\text { higher in 2006, 5.1 percentage points higher in 2007, 6.5 percentage points higher in 2008; similar trends were observed for per- } \\
\text { centage of patients with MPR at least 80\%. }\end{array}$
\end{tabular}

- Among DMP participants, percentages complying with recommended tests and services were higher in VBID group than in nonVBID group (e.g., percentage point differences in 2008: 4.5 for HbAlc tests, 5.0 for lipid tests, 7.7 for PCP visits, 4.0 for urinalysis).

- In non-DMP group, few significant differences between VBID and non-VBID groups, but (a) OAD MPR was 3.8-4.7 percentage points higher with VBID in 2006 and 2007 (but not 2008) and (b) compliance in the first year was significantly lower with VBID for HbAlc (5.2 percentage points) and urinalysis (3.1 percentage points).

- In DMP group, diabetes-related medical costs were lower and medication costs higher in all 3 years for VBID than non-VBID group; authors estimated an ROI of 1.33 .

- No consistent cost pattern for VBID vs. no VBID in non-DMP group.

\begin{tabular}{l|l} 
Comments & Enhanced compliance with screening/monitoring tests and medical examinations was described as an "effect" of VBID although
\end{tabular} the VBID intervention changed drug copayments only.

- Report measured "ROI" on total costs paid by all sources (including the patient cost share) instead of payer costs. Thus, cost to payer was not reported; results do not represent the ROI that should be expected by the payer; and description of VBID program as "cost-neutral" does not accurately describe the payers' cost outlays.

- Cost of DMP was not reported although the DMP was extensive and the positive results for VBID were limited to DMP participants. Study report acknowledged that "to obtain a full cost estimate, some form of assignment into disease management, to measure [DMP] effects and costs, would be necessary."

- Criteria for invitation into the DMP were not specified, making the clinical characteristics of the sample unclear (e.g., any diabetes diagnosis, use of particular services, such as hospitalizations, for diabetes, or what, specifically?); proportion of patients who opted-out not reported for the comparison group.

- The authors apparently measured MPR as zero (0) for patients using diet and exercise alone, regardless of whether any medication was prescribed-for example, pre-intervention insulin MPR was reported as $10 \%$ or less for all 4 groups.

\begin{tabular}{|c|c|}
\hline Gibson $(2011 b)^{70}$ & $\begin{array}{l}\text { Overview: Study of a "large, global pharmaceutical firm" that implemented a VBID (copayment reduction) on January 1, 2005, for } \\
\text { drugs to treat asthma (SABAs, LABAs, leukotriene modifiers, inhaled corticosteroids, methylxanthines, mast cell stabilizers, and } \\
\text { combinations); HTN (ACE inhibitors, ARBs, diuretics, alpha-2 agonists, aldosterone receptor blockers); and diabetes (insulin and } \\
\text { OADs). In addition to the VBID, DMPs for "asthma, cardiac conditions, and diabetes were also implemented for enrollees in the com- } \\
\text { pany's indemnity and point-of-service plans in } 2005 \text { and ... across all of the company's self-insured plans in 2007," with educational } \\
\text { materials about the programs "communicated to all employees ... starting in the fourth quarter of 2004." }\end{array}$ \\
\hline Sample & $\begin{array}{l}\text { Enrollees aged 18-64 years who were enrolled for a minimum of } 1 \text { year prior to the first quarter of enrollment post-implementation } \\
\text { and for at least } 2 \text { quarters after implementation; no other sampling requirements were imposed, and the sample included "enrollees } \\
\text { who did not use any medical services." }\end{array}$ \\
\hline Groups & $\begin{array}{l}\text { Intervention: } \mathrm{n}=25,784 \text { before matching, } 25,065 \text { after matching; pre-intervention copayments not clear but appear to be } 20 \% \\
\text { coinsurance in community pharmacies and } 10 \% \text { in mail order pharmacy with minimum } \$ 10 \text { and maximum } \$ 40 \text {; post-intervention } \\
\text { copayments were } 10 \% \text { coinsurance in community pharmacies and } 7.5 \% \text { in mail order pharmacies with the same minimum and } \\
\text { maximum. No quantitative information about cost-sharing was provided except that multivariate models estimated that in the first } \\
\text { post-implementation year, "enrollees paid } \$ 4 \text { less on average for VBID medications with the VBID ( } \$ 11.16 \text { ) than without the VBID } \\
\text { (\$15.37);" the difference increased to about } \$ 5 \text { per enrollee in the third post-implementation year; and, "overall cost-sharing amounts } \\
\text { declined } 7.2 \% \text { for VBID enrollees" from Q1 } 2004 \text { to Q4 } 2007 \text {. Brand drugs manufactured by the employer were provided free of } \\
\text { charge to all enrollees in both periods. } \\
\text { Comparison: } n=154,444 \text { before matching, } 25,065 \text { after matching; enrollees insured in } 4 \text { "empirically similar" firms with data in } \\
\text { the Thomson Reuters MarketScan database were propensity matched for probability of being in the intervention group based on } \\
\text { demographic characteristics, health status (CCI and psychiatric diagnosis groups), employment characteristics (e.g., salary vs. hourly, } \\
\text { active vs. retiree), relationship to employee, ZIP-level income, and number of quarters of enrollment. No quantitative information } \\
\text { about copayments paid in either period was provided except that: (a) "patient cost-sharing did not change in the pre-period" and (b) } \\
\text { "cost-sharing increased } 12 \% " \text { from Q1 } 2004 \text { to Q4 } 2007 \text {. }\end{array}$ \\
\hline
\end{tabular}




\section{What Do We Really Know About VBID? \\ Quality of the Evidence and Ethical Considerations for Health Plan Sponsors}

\section{APPENDIX Summary of Recent Observational Studies of Copayment Reductions and Medication Adherence ${ }^{a}$ (continued)}

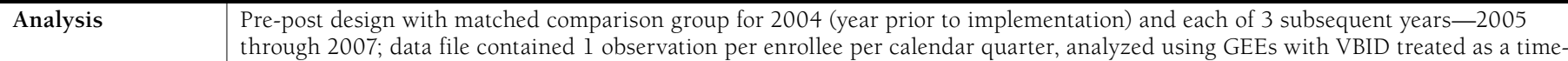
varying effect (trend) set to zero in Q1 2005 and 11 in Q4 2007. Outcomes were (a) use rate (percentage with at least 1 claim in therapeutic class); (b) adherence based on PDC (at least 50\% for asthma, at least $80 \%$ for HTN and diabetes); (c) number of 30-day equivalent fills both overall and for VBID classes; and (d) total "eligible charges" for drugs and medical services.

\begin{tabular}{l|l} 
Results & - Average drug spending on VBID medications in Q4 2007 was \$68 for VBID group and \$51 for comparison group.
\end{tabular}

- For diabetes drugs, use rates and number of fills did not significantly differ in any year; adherence was lower for the VBID group in the first 2 post-implementation years and not significantly different in the third year.

- For asthma drugs, no significant differences on most measures in most years; only exception was that adherence to asthma medications (but not use rates or number of fills) was significantly higher in the third year only.

- For HTN drugs, adherence, user percentage, and number of fills were significantly higher in the VBID group in all years.

- GEEs showed no significant differences on any measure of total charges (prescription drug, medical, or total) in any of the 3 years.

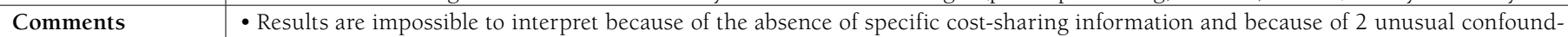
ing factors-provision of coincident DMP and of unnamed brand drugs free-of-charge in the intervention group.

- Abstract implies that adherence was higher with VBID in all classes, but data tables indicate that adherence and medication use increased only for HTN medications.

- Authors "raise the prospect that this program may have saved the company money by reducing other medical costs" because "clinical effects such as changes in glucose levels, blood pressure, and lung functioning might have occurred," but these effects were not measured.

- Cost-sharing change for the VBID program appears to be small (only a $7.2 \%$ decrease), making it likely that results for the intervention group are at least partly attributable to the DMP or to another confounding factor.

- "Eligible charges" were not specifically defined (perhaps total provider-billed charges) but do not appear to represent the payer's outlays; thus, the authors' description of the intervention as "mostly cost-neutral to the company" appears to be incorrect.

- Discussion describes nonsignificant cost differences as if they were significant.

- Authors indicate that results were similar in a subset of enrollees with pre-intervention drug use; however, description of results in text does not match exhibit table, and the table names what appears to be the wrong pharmaceutical company (employer). Thus, these results cannot be interpreted.

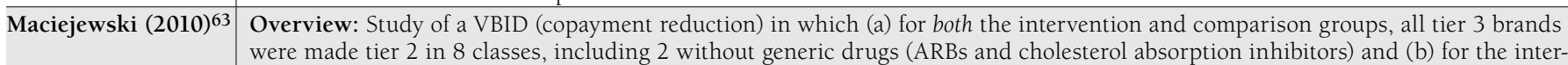
vention group, generic copayments were waived in 6 classes, effective January 1, 2008

$\begin{array}{ll}\text { Sample } & \begin{array}{l}\text { Enrollees of BCBS-NC who were continuously enrolled from January } 2007 \text { thrc } \\ \text { tion" from at least } 1 \text { of the study classes (time period for criterion not clear). }\end{array}\end{array}$

Groups $\quad$ Intervention: Enrollees whose employers opted into the VBID ( $\mathrm{n}=638,796) ; \mathrm{n}=5,077$ metformin, 15,605 diuretics, 14,250 ACE inhibitors, 11,137 beta-blockers, 18,346 statins, 7,191 CCBs, 7,445 ARBs, 4,019 cholesterol absorption inhibitors. Pre-intervention copayments (reported as means per claim) were $\$ 10.74-\$ 11.38$ generic, $\$ 33.79-\$ 34.39$ brand, and overall: $\$ 13-\$ 17$ for ACE inhibitors, beta-blockers, diuretics, and metformin; $\$ 22-\$ 25$ for statins and CCBs; $\$ 36-\$ 37$ for ARBs and cholesterol absorption inhibitors. ${ }^{d}$ Post-intervention copayments were $\$ 0$ generic, $\$ 30.50-\$ 30.75$ brand, and overall not reported.

Comparison: Enrollees of BCBS-NC whose employers did not opt in ( $\mathrm{n}=638,091) ; \mathrm{n}=2,826$ metformin, 9,137 diuretics, 7,668 ACE inhibitors, 6,343 beta-blockers, 10,162 statins, 4,099 CCBs, 4,514 ARBs, 2,291 cholesterol absorption inhibitors. Pre-intervention copayments were not reported for generics, were same as intervention group for brands, and overall: \$14-\$18 for ACE inhibitors, beta-blockers, diuretics, and metformin; $\$ 24-\$ 27$ for statins and CCBs; $\$ 39-\$ 40$ for ARBs and cholesterol absorption inhibitors. ${ }^{\mathrm{d}}$ Post-intervention copayments were not reported except that brand copayments were the same as in the intervention group.

\begin{tabular}{|c|c|}
\hline Analysis & $\begin{array}{l}\text { DID (GLM) model of MPR with person-year as unit of analysis, controlling for age, sex, ERG comorbidity burden measure, and pre- } \\
\text { intervention medication burden (count of medications, mean copayments, at least } 190 \text {-day supply, GDR).e }\end{array}$ \\
\hline Results & $\begin{array}{l}\text { - Pre-to-post changes in MPR (percentage points) were slightly higher for intervention than comparison group in classes with gener- } \\
\text { ic copayment waiver: metformin } 3.8 \text {, diuretics } 3.3, \text { ACE inhibitors } 2.9 \text {, beta-blockers } 2.5 \text {, statins } 1.8, \text { CCBs } 1.5 \text {. } \\
\text { - In } 2 \text { classes consisting entirely of brand drugs (i.e., copayment reductions in both groups), groups did not significantly differ. } \\
\text { - Filling at least } 1 \text { prescription with a } 90 \text {-day supply was associated with MPR increases of } 17 \text { to } 22 \text { percentage points. } \\
\text { - Authors stated that "significantly higher medication costs given the number of people participating in the program" posed a poten- } \\
\text { tial threat to "the long-term viability of this innovative policy change." }\end{array}$ \\
\hline Comments & $\begin{array}{l}\text { - Methodologically strengthened by comparison of } 6 \text { VBID (generic drug copayment waiver) classes with } 2 \text { drug classes (ARBs and } \\
\text { cholesterol absorption inhibitors) consisting entirely of brand drugs (copayments reduced in both groups). } \\
\text { - Title includes the term "targeted patients," but no patients were excluded from copayment reduction in the } 6 \text { drug classes studied } \\
\text { (i.e., there was no targeting for secondary prevention or specific risk factors). } \\
\text { - Abstract and discussion erroneously indicate that the study VBID included both generic and brand copayment reductions; actually, } \\
\text { brand copayments were reduced in both the intervention and comparison groups. } \\
\text { - GDR was reported pre-intervention but not post-intervention. }\end{array}$ \\
\hline
\end{tabular}




\section{What Do We Really Know About VBID? \\ Quality of the Evidence and Ethical Considerations for Health Plan Sponsors}

\section{APPENDIX Summary of Recent Observational Studies of Copayment Reductions and Medication Adherence ${ }^{a}$ (continued)}

\begin{tabular}{l|l}
\hline Sedjo (2008)62 & Naturalistic study of patent expiration for simvastatin effective June 23, 2006; there was no intervention-enrollees who used
\end{tabular} brand simvastatin prior to expiration were compared with those who used other brand statin drugs (no copayment decrease). Study patients were aged 18 years or older and continuously enrolled from June 2005 through May 2007.

Groups $\quad$ Copayment reduction group: Commercially insured health plan enrollees with at least 1 claim for brand simvastatin from June through August 2005 and at least 1 generic simvastatin claim from June through August 2006 ( $n=13,319)$. Pre-expiration copayment was a mean $\$ 14.60$; post-expiration copayments not reported but patients were subgrouped by amount of reduction (subgroup counts not specified)

Comparison group: Commercially insured health plan enrollees with at least 1 claim for a brand statin (not simvastatin) from June through August 2005 and at least 1 claim for any statin (not simvastatin) from June through August 2006 ( $n=26,569$ ); matched to intervention group patients on incident use (binary indicator) and pre-expiration copayment $\pm \$ 2$. Pre-expiration copayment was a mean $\$ 14.57$; post-expiration copayments not reported.

\begin{tabular}{l|l}
\hline Analysis & Bivariate and multivariate (linear regression modeling) by-group comparisons of change in MPR from pre-expiration to post-expira-
\end{tabular} tion periods; MPR represented any statin drug "to allow for switching within the statin class" and was measured in each period from the first fill date through the subsequent 270 days. Secondary outcomes included percentage adherent (MPR at least 80\%) and elasticity (percentage change in MPR divided by percentage change in copayment). Multivariate analyses controlled for age, sex, incident statin use, chronic disease score, and pre-expiration MPR and copayments.

\begin{tabular}{l|l} 
Results & $\bullet$ MPR declined in both groups: $-0.17 \%$ in copayment reduction group and $-1.67 \%$ in comparison group; multivariate analyses sug-
\end{tabular} gested $0.52 \%$ adjusted mean MPR increase in copayment reduction group and $2.02 \%$ adjusted mean MPR decrease in comparison group.

- Increase in MPR to at least $80 \%$ occurred in $10.5 \%$ of reduction and $10.0 \%$ of comparison patients.

- Decrease in MPR to below $80 \%$ occurred in $12.1 \%$ of reduction and $11.3 \%$ of comparison patients.

- Elasticity 0.02 for reductions of $\$ 0$ to $\$ 5$ and -0.02 for reductions of more than $\$ 15$ (i.e., a $10 \%$ decrease in copayment was associated with a 0.2 percentage point increase in MPR).

Comments $\quad$ - Discontinuation rates not reported; results reflect only patients with statin use in both periods.

- Neither post-change copayments nor counts for copayment change groups were reported, making it difficult to assess the overall magnitude of the cost-sharing change.

- Mean pre-expiration MPRs were high (85\%-89\%) in both groups; results may not generalize to less adherent patient populations.

Zeng (2010) ${ }^{69}$ Study of the movement of "a comprehensive list of diabetes medications" into tier l effective January 1, 2007; tier 1 drugs included SSB (e.g., pioglitazone, rosiglitazone/metformin, exenatide) and MSB (e.g., Amaryl as well as glimepiride). "Most diabetes medications and supplies in tier 2" and "a few in tier 3" were "moved ... into [VBID]."

Sample

Groups

Commercially insured HMO enrollees aged 18 years or older on January 1, 2006, with at least 1 diabetes medication claim in 2005, 2006, and 2007; continuously enrolled from January 1, 2005, through December 31, 2007.

Intervention: Employees and dependents of the clinic that owned the HMO (n=71); pre-intervention copayments were $\$ 10$ for generic, $30 \%$ for tier 2 , and $50 \%$ for tier 3, for an overall mean of $\$ 18.80$ per 30-day claim. Post-intervention copayments were $\$ 10$ for tier 1 and not reported for tier 2 and tier 3, for a mean of $\$ 10.40$ per 30-day claim.

Comparison: Enrollees of the same HMO who were not VBID enrolled ( $\mathrm{n}=5,037$, of whom 639 were selected at random for analysis); pre-intervention copayments are not entirely clear but appear to be the same structure as the intervention group's, with a mean of $\$ 14.30$ per 30-day claim. Post-intervention copayments were "unchanged" and a mean of $\$ 18.80$ per 30-day claim.

\begin{tabular}{l|l} 
Analysis & Propensity-score weighted DID analysis in which each enrollee had 2 observations, one for 2006 and the other for 2007 ; outcomes
\end{tabular} were PDC and percentage adherent, defined as PDC of at least $80 \%$. Propensity score was based on age, sex, mean diabetes medication copayment, insulin use, and comorbidities in 2005 measured using RxRisk categories.

\begin{tabular}{l|l} 
Results & PDC (after propensity-score weighting) 0.88 pre-intervention in both groups; changed to 0.90 in intervention group and
\end{tabular} unchanged in comparison group; nonsignificant in multivariate analysis

- Percent adherent (after propensity-score weighting) changed from $75.3 \%$ to $82.5 \%$ in intervention and from $79.1 \%$ to $78.5 \%$ in comparison group; OR of adherence in logistic regression controlling for demographics, insulin use, and RxRisk score $=1.56,95 \%$ confidence interval $=1.04-2.34$.

- Percentage point change in use of TZDs + 1.3 in intervention, -0.6 in comparison group; authors noted "moderate" shift toward increased use of brand drugs in VBID group.

Comments
- Difficult to interpret without more specific information about the cost-sharing amounts and tier assignments.

- RxRisk category assignment used in comorbidity measurement and logistic regression may contain errors; study report indicates that $10 \%$ of study sample (mean age approximately 58 years) had cystic fibrosis.

- Study abstract does not mention the finding that the by-group differences in PDC change were not significant.

- Although comparison group copayments were described as "unchanged," they increased from pre- to post-intervention by $31 \%$; however, the increase was less in the propensity-weighted analysis.

- $\mathrm{N}$ of cases in intervention group was small, and the external validity is unclear.

- Mean pre-intervention PDCs were high (86\%-88\%) in both groups; results may not generalize to less adherent patient populations.

- Transparent reporting of pre- and post-intervention values for outcome measures. 


\section{What Do We Really Know About VBID? \\ Quality of the Evidence and Ethical Considerations for Health Plan Sponsors}

\section{APPENDIX Summary of Recent Observational Studies of Copayment Reductions and Medication Adherence ${ }^{a}$ (continued)}

\begin{tabular}{|c|c|}
\hline Roebuck $(2011)^{31}$ & $\begin{array}{l}\text { Study measured association between MPR and all-cause health care expense; not a study of copayment reduction, and there was no } \\
\text { intervention. }\end{array}$ \\
\hline Sample & $\begin{array}{l}\text { Commercially insured members of } 9 \text { health plans with primary, secondary, or tertiary diagnoses on at least } 2 \text { outpatient visit claims } \\
\text { or } 1 \text { inpatient stay or ER visit claim for any of } 4 \text { chronic conditions: CHF }(n=16,353) \text {, HTN }(n=112,757) \text {, diabetes (type } 1 \text { or type } 2 \text {, } \\
n=42,080) \text {, and dyslipidemia }(n=53,041) \text {; all were enrolled continuously from January } 1,2005 \text {, through June } 30,2008 \text {. }\end{array}$ \\
\hline Analysis & $\begin{array}{l}\text { Linear fixed-effects modeling of panel data in which each patient contributed } 3 \text { (yearly, July through June) observations-2005/2006 } \\
\text { through 2007/2008; results represent marginal effects. Models controlled for demographics, CCI, and time trends. MPR for each } \\
\text { condition represented "the average of the [MPRs] for all therapeutic classes for each chronic disease, weighted by the days' supply in } \\
\text { each therapeutic class," with zero (0) adherence assumed for patients with a diagnosis but no drug treatment. Adherence was defined } \\
\text { as MPR of at least } 80 \% \text {, and there was no assessment of continuous MPR. Outcomes were } 3 \text { measures of annual all-cause service use: } \\
\text { inpatient days, ER visits, outpatient physician visits; and } 3 \text { measures of all-cause cost: pharmacy, medical, and total. }\end{array}$ \\
\hline
\end{tabular}

\begin{tabular}{l|l} 
Results & - Adherence was associated with fewer all-cause inpatient days annually (1.18 for patients with dyslipidemia, approximately 2 for
\end{tabular} patients with HTN or diabetes, 5.72 for patients with CHF).

- Marginal effect for inpatient days was greater for those aged 65 years or older (1.88 dyslipidemia, 3.41 diabetes, 3.14 HTN, 5.87 CHF).

- Associations of adherence with all-cause ER visit use (reduction of 0.01-0.04 visits annually) and outpatient physician visits (increase of about 1 visit annually for patients with CHF and less than 0.5 visits for the remaining patients) were small.

- All-cause medical services costs were lower and pharmacy costs higher for adherent patients; net annual savings estimated at $\$ 1,258$ dyslipidemia, $\$ 3,576$ diabetes, $\$ 3,908$ HTN, $\$ 7,823$ CHF.

\begin{tabular}{l|l} 
Comments & Transparent and clear report of study methods and limitations.
\end{tabular}

- Decision to assume zero adherence for patients not treated with medication is inconsistent with treatment guidelines for HTN and dyslipidemia and partially inconsistent with guidelines for type 2 diabetes.

- Results represent all-cause (not disease-specific) utilization, and there was no assessment of whether health care utilization could reasonably be clinically attributable to medication adherence or nonadherence; sole reliance on fixed-effects modeling to establish causality.

- As the authors acknowledge, fixed-effects modeling does not adjust for confounders that change during the study period, such as a patient's decision to improve both medication adherence and other health-related behaviors simultaneously (i.e., new "healthy adherence" behaviors).

- MPR denominator was apparently not adjusted for inpatient days when patients would be receiving drugs from the hospital or nursing home (not measured with pharmacy claims).

- Analyses and interpretation did not account for possibility that medications could have been obtained through community pharmacy generic drug discount programs during the study period (July 2005 through June 2008).

- Although authors suggest that findings have potential implications for VBID, association of copayment with adherence or utilization was not assessed.

a All information reported in this table reflects both the study reports and any online appendices, which can be accessed using hyperlinks in the study reports. No study of VBID assessed changes in GDR, generic drug utilization PMPM, or payers' costs.

${ }^{b}$ This assessment may be an error because it sounds implausible; however, text indicates: "Users of tier 1 and tier 2 medications in the control group ... had no changes in their copayment of $\$ 10$ during the study period." 29

cSee Mahoney (2005). ${ }^{77}$

${ }^{d}$ For ARBs and cholesterol absorption inhibitors (i.e., containing ezetimibe), which were 100\% brand, the average pre-intervention copayment reported in the methodological appendix exceeds the top of the pre-intervention brand copayment range reported in the text for reasons that are not clear from the study report.

'The time period for measurement of the GDR covariate was not clear in the study report. The description appears in the methodological appendix in a section describing "pre-period medication burden;" however, the description of the variable states that the authors "controlled for the [GDR] ... for the immediate financial benefit of the [VBID] program by switching from brand to generic medications." 63

fList of drugs for Zeng et al. VBID program is in a study appendix at http://www.ispor.org/Publications/value/ViHsupplementary/ViH13i6_Zeng.asp. Our assessment that all drugs in the study appendix were tier 1 may be inaccurate, but the text refers to them as tier 1 medications and the study appendix does not specify tier status. Mean copayments shown in this Appendix are per 30-day supply before propensity score weighting. Propensity-score weighted copayments for the intervention and comparison groups were, respectively, $\$ 15.30$ and $\$ 14.60$ pre-intervention and $\$ 10.10$ and $\$ 15.10$ post-intervention. 69

$A C E=$ angiotensin-converting enzyme inhibitor; $A R B=$ angiotenson II receptor blocker; BCBS-NC=Blue Cross Blue Shield of North Carolina; $C C B=c a l c i u m$ channel blocker; $C C I=$ Charlson Comorbidity Index; $C H F=$ congestive heart failure; $D C=$ discontinuation; $D I D=$ difference-in-difference; $D M P=$ disease management program; $E R=$ emergency room; $E R G=$ Episode Risk Groups classification model, GDR=generic dispensing ratio; GEE = generalized estimating equation; GLM=generalized linear model; $\mathrm{Hb}=$ hemoglobin; $H M O=$ health maintenance organization; $H T N=$ hypertension; $L A B A=$ long-acting inhaled beta agonist; MPR=medication possession ratio; $N A=$ not applicable; $O A D=$ oral antidiabetic drug; $O R=$ odds ratio; $P D C=$ proportion (or percentage) of days covered; $P B M=$ pharmacy benefits management company; $P M P M=$ per member per month; $Q=$ quarter; $R O I=$ return-on-investment; $R T M=$ regression to the mean; $S A B A=$ short-acting beta agonist; $S S B=$ single-source brand; $T Z D=$ thiazolidinedione; VBID = value-based insurance design (implemented as drug copayment reduction in these studies); vs =versus. 